\title{
Designing a Multifunctional Catalyst for the Direct Production of Gasoline-Range Isoparaffins from $\mathrm{CO}_{2}$
}

\author{
Abhay Dokania, Samy Ould-Chikh, Adrian Ramirez, Jose Luis Cerrillo, Antonio Aguilar, Artem Russkikh, \\ Ahmed Alkhalaf, Idoia Hita, Anastasiya Bavykina, Genrikh Shterk, Nimer Wehbe, Alain Prat, Eric Lahera, \\ Pedro Castaño, Emiliano Fonda, Jean-Louis Hazemann, and Jorge Gascon*
}

Cite This: https://doi.org/10.1021/jacsau.1c00317

Read Online

\section{ACCESS \\ 山lll Metrics \& More \\ 回 Article Recommendations \\ (s) Supporting Information}

ABSTRACT: The production of carbon-neutral fuels from $\mathrm{CO}_{2}$ presents an avenue for causing an appreciable effect in terms of volume toward the mitigation of global carbon emissions. To that end, the production of isoparaffin-rich fuels is highly desirable. Here, we demonstrate the potential of a multifunctional catalyst combination, consisting of a methanol producer ( $\mathrm{InCo}$ ) and a $\mathrm{Zn}$ modified zeolite beta, which produces a mostly isoparaffinic hydrocarbon mixture from $\mathrm{CO}_{2}$ (up to $\sim 85 \%$ isoparaffin selectivity among hydrocarbons) at a $\mathrm{CO}_{2}$ conversion of $>15 \%$. The catalyst combination was thoroughly characterized via an extensive complement of techniques. Specifically, operando X-ray absorption spectroscopy (XAS) reveals that $\mathrm{Zn}$ (which plays a crucial role of providing a hydrogenating function, improving the stability of the

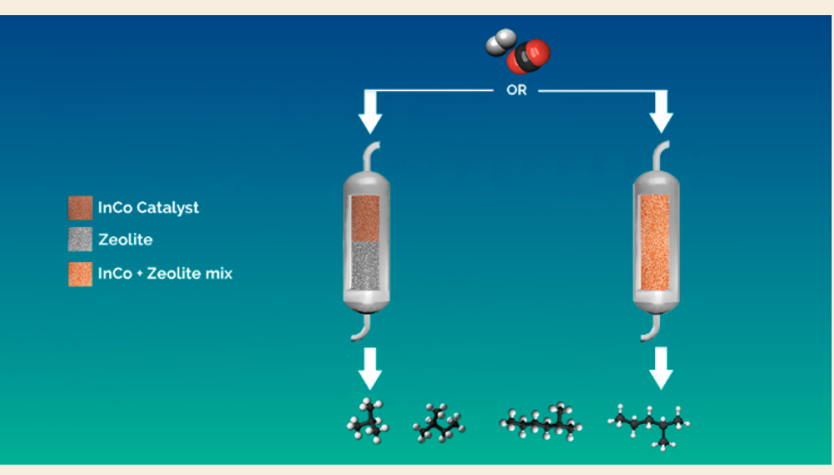
overall catalyst combination and isomerization performance) is likely present in the form of $\mathrm{Zn}_{6} \mathrm{O}_{6}$ clusters within the zeolite component, in contrast to previously reported estimations.

KEYWORDS: $\mathrm{CO}_{2}$ hydrogenation, zeolite catalysis, methanol synthesis, reactor engineering, operando characterization, XAS, zeolite modification

\section{INTRODUCTION}

The urgent global call to action for combating climate change requires innovative solutions for addressing the ever-increasing levels of atmospheric $\mathrm{CO}_{2}$. Among the multiple solutions proposed, the concept of a "circular carbon economy" stands out, since it advocates for approaches toward the mitigation of $\mathrm{CO}_{2}$ emissions without a radical overhaul of the current infrastructure. ${ }^{1}$ This concept advances the creation of fuels and chemicals by direct air capture (DAC) of $\mathrm{CO}_{2}{ }^{2}$ and subsequent hydrogenation to the product of choice using appropriate processes and catalysts. Fuel production via this route can have a sizable effect in terms of volume (mitigation of $>5 \mathrm{Gt}$ of $\mathrm{CO}_{2}$ emissions per year) toward the reduction of overall global $\mathrm{CO}_{2}$ emissions. ${ }^{3,4}$ Thus, by recycling the $\mathrm{CO}_{2}$ present in the atmosphere, we can avoid additional carbon emissions and eschew the need for a significant overhaul of the transportation infrastructure. Another advantage to consider for this method of fuel generation is the fact that we can completely avoid $\mathrm{SO}_{x}$ and $\mathrm{NO}_{x}$ emissions typically associated with impurities in conventional fossil fuels. ${ }^{5}$ Although the implementation of this proposal is feasible and has the potential to cause a substantial effect on the landscape of energy and climate change, significant challenges need to be overcome before such a technology can be employed on a realistically large scale. One of the greatest challenges identified is the enormous discrepancy between the renewable energy required for conversion of $\mathrm{CO}_{2}$ to fuels and the actual current renewable energy production capacity. ${ }^{6}$ This generated energy needs to meet the twofold challenges of $\mathrm{DAC}$ of $\mathrm{CO}_{2}$ and generation of renewable $\mathrm{H}_{2}$ via water electrolysis.

Assuming that these challenges can be overcome, the most proficient method for the conversion of $\mathrm{CO}_{2}$ to fuels is thermocatalytic conversion. This method has the dual benefit of high product yields in comparison to other alternatives (e.g., electrocatalysis or photocatalysis) and the fact that $\mathrm{CO}_{2}$ hydrogenation is an exothermic reaction, implying that reaction temperatures can be maintained (typically 250-400 ${ }^{\circ} \mathrm{C}$ ) without a high additional energy input by using proper heat integration. A significant body of literature exists illustrating the advantages of thermochemical multifunctional

Received: July 19, 2021 
catalysis (i.e., the combination of a metal/metal oxide and a zeolite as a multifunctional catalyst) for the hydrogenation of $\mathrm{CO}_{2}$ to useful products. ${ }^{7-12}$ Chief among the advantages is the sheer tunability of the product distribution that can be achieved by choosing the appropriate components of the multifunctional catalyst. This has repeatedly been demonstrated in the literature with products ranging from light olefins $^{13-16}$ to aromatics ${ }^{17-21}$ and paraffins ${ }^{22-29}$ being obtained by employing complementary configurations of a multifunctional catalyst.

While most of the focus for the production of valuable chemicals via multifunctional thermocatalytic hydrogenation of $\mathrm{CO}_{2}$ has been on light olefins and aromatics, the production of gasoline-range hydrocarbons (isoparaffins) has received far less attention, ${ }^{30}$ with only a few reports being found in the literature targeting this product slate from $\mathrm{CO}_{2}{ }^{22,26-29,31}$ This discrepancy becomes especially significant when one considers the fact that isoparaffins have significantly higher octane numbers in comparison to linear paraffins (Table 1). Fuels

\section{Table 1. Research Octane Number (RON) and Motor} Octane Number (MON) of Various Paraffins ${ }^{a}$

\begin{tabular}{lrr}
\multicolumn{1}{c}{ paraffin } & RON & MON \\
2-methylpropane (isobutane) & 102.1 & 97.0 \\
n-pentane & 61.8 & 63.2 \\
2-methylbutane (isopentane) & 93.0 & 89.7 \\
$n$-hexane & 24.8 & 26.0 \\
C $_{6}$ monomethyls $^{b}$ & 73.9 & 73.4 \\
2,2-dimethylbutane & 91.8 & 93.4 \\
2,3-dimethylbutane & 104.3 & 94.2 \\
$n$-heptane & 0.0 & 0.0 \\
C $_{7}$ monomethyls $^{b}$ & 52.0 & 55.0 \\
C $_{7}$ dimethyls & & 95.6 \\
2,2,3-trimethylbutane & 92.8 & 101.3
\end{tabular}

${ }^{a}$ The values are derived from ref $32 .{ }^{b}$ Branched isomers with a single substituted methyl group. ${ }^{c}$ Branched isomers with two substituted methyl groups.

with a higher octane number provide superior antiknock performance in engines as well as better fuel efficiency. Thus, it is imperative to target this product range due to the significant role it can play in $\mathrm{CO}_{2}$ emission mitigation.

In this work, inspired by Ruddy et al., ${ }^{33,34}$ who recently demonstrated that it is possible to convert dimethyl ether (DME) to isoparaffins by using a Cu-modified beta zeolite catalyst in the presence of $\mathrm{H}_{2}$, we show that isoparaffins can also be directly produced from $\mathrm{CO}_{2}$. We have achieved this by combining an InCo catalyst previously reported by us ${ }^{35}$ and zeolite beta (with or without $\mathrm{Zn}$ modification). Here, the InCo catalyst is responsible for the production of methanol from $\mathrm{CO}_{2}$, while the zeolite catalyzes the transformation of methanol to hydrocarbons (MTH). Furthermore, operando $\mathrm{X}$-ray absorption spectroscopy (XAS) measurements were carried out for the combined InCo + beta/InCo + Zn-beta systems and the structural changes associated with $\mathrm{Co}$ and $\mathrm{Zn}$ during the course of the reaction have been elucidated. Although other studies have reported operando XAS measurements for $\mathrm{CO}_{2}$ hydrogenation, they were performed on standalone catalysts producing methanol from $\mathrm{CO}_{2}{ }^{36,37}$ Thus, this study, to the best of our knowledge, represents the first of its kind wherein an operando XAS study of a multifunctional catalyst combination producing hydrocarbons from $\mathrm{CO}_{2}$ has been carried out.

\section{EXPERIMENTAL SECTION}

\section{Chemicals}

Aqueous ammonia solution (28-30 wt \%, Acros Organics), hydrogen peroxide ( $24 \mathrm{vol} \%$, VWR Chemicals), cobalt acetate tetrahydrate $\left(\mathrm{Co}\left(\mathrm{CH}_{3} \mathrm{COO}\right)_{2} \cdot 4 \mathrm{H}_{2} \mathrm{O}\right.$, Aldrich), indium acetate $\left(\mathrm{In}\left(\mathrm{CH}_{3} \mathrm{COO}\right)_{3}\right.$, Alfa Aesar) and zinc nitrate hexahydrate $\left(\mathrm{Zn}\left(\mathrm{NO}_{3}\right)_{2} \cdot 6 \mathrm{H}_{2} \mathrm{O}\right.$, Aldrich) were used as received. Zeolite beta $\left(\mathrm{SiO}_{2} / \mathrm{Al}_{2} \mathrm{O}_{3}=38\right.$, Zeolyst $)$ was purchased in ammonium form and calcined at $550{ }^{\circ} \mathrm{C}$ for $7 \mathrm{~h}$ in a muffle furnace in order to obtain the $\mathrm{H}$ form before use.

\section{Catalyst Preparation}

The InCo catalyst was prepared as described previously using the inverse coprecipitation method. ${ }^{35}$ Briefly, a basic solution was made using $35 \mathrm{~mL}$ of an $\mathrm{NH}_{3}$ solution, $1.35 \mathrm{~g}$ of $\mathrm{H}_{2} \mathrm{O}_{2}$, and addition of water to make up the volume to $315 \mathrm{~mL}$. Separately, a $35 \mathrm{~mL}$ aqueous solution containing $2.6 \mathrm{~g}$ of $\mathrm{Co}\left(\mathrm{CH}_{3} \mathrm{COO}\right)_{2}$ and $1.3 \mathrm{~g}$ of $\mathrm{In}\left(\mathrm{CH}_{3} \mathrm{COO}\right)_{3}$ hydrate salts was prepared and completely dissolved via sonication. After total dissolution of the salts, this solution was added dropwise into the basic solution $\left(2 \mathrm{~mL} \mathrm{~min}^{-1}\right)$. The suspension was stirred for an additional $30 \mathrm{~min}$ after the addition of the salt solution. Then, the solid was recovered and washed with water using centrifugation, followed by an overnight drying process at $60{ }^{\circ} \mathrm{C}$. The obtained product was pretreated under reaction conditions of $300^{\circ} \mathrm{C}$, 50 bar, $\mathrm{CO}_{2}: \mathrm{H}_{2}=1: 4$, and a GHSV of $15000 \mathrm{~mL} \mathrm{~g}_{\text {cat }}{ }^{-1} \mathrm{~h}^{-1}$ for $24 \mathrm{~h}$ prior to study.

The Zn-beta was obtained as follows. Zeolite beta was initially dried under vacuum at $120{ }^{\circ} \mathrm{C}$ overnight. The dried beta was impregnated with a solution of $\mathrm{Zn}\left(\mathrm{NO}_{3}\right)_{2}$ using incipient wetness impregnation. This sample was again dried under vacuum at $120^{\circ} \mathrm{C}$ overnight. After the second drying step, the $\mathrm{Zn}$-beta was calcined in a muffle furnace at $550{ }^{\circ} \mathrm{C}$ for $7 \mathrm{~h}$. The $\mathrm{Zn}$-beta sample thus obtained was pelletized, crushed, and sieved to a particle size of $150-250 \mu \mathrm{m}$ prior to use. $\mathrm{Zn}$ loading on the $\mathrm{Zn}$-beta sample was measured by ICP and was found to be $4.43 \%$ by weight.

\section{Catalytic Testing}

Catalytic tests were performed on an Avantium Flowrence XD catalytic testing unit with four parallel channels operated in a fixedbed configuration. In a typical experiment, $50 \mathrm{mg}$ of the InCo catalyst and $50 \mathrm{mg}$ of the zeolite were loaded into a stainless steel reactor. One of the channels was used without catalyst as blank. A premixed feed of $\mathrm{CO}_{2}, \mathrm{H}_{2}$, and $\mathrm{He}$ (internal standard) was supplied to each reactor in a volumetric ratio of 1:4:0.4 with a total flow of $13.5 \mathrm{~mL}$ $\mathrm{min}^{-1}$ per reactor. The reaction pressure was set to $50 \mathrm{bar}$ and the reaction temperature to $300{ }^{\circ} \mathrm{C}$, unless mentioned otherwise. The effluent from the reactor was diluted with $\mathrm{N}_{2}\left(10 \mathrm{~mL} \mathrm{~min}{ }^{-1}\right.$ per reactor) at the reactor outlet and automatically supplied for online gas chromatographic (GC) analysis. Gas product analysis was performed using an Agilent 7890B GC instrument with two sample loops. After the loops were flushed for $20 \mathrm{~min}$, the products were injected. One sample loop was directed toward the TCD channel with two Haysep precolumns and a MS5A column, where $\mathrm{He}, \mathrm{H}_{2}, \mathrm{CH}_{4}$, and $\mathrm{CO}$ were separated. Gases that have longer retention times in comparison to $\mathrm{CO}_{2}$ on the Haysep column (Column 4 Haysep Q 0.5 m G359180023) were back-flushed. A further separation of permanent gases was done on another Haysep column (Column 5 Haysep Q $6 \mathrm{Ft}$ G3591-80013) to separate $\mathrm{CO}_{2}$ before going to a MS5A column. The other sample loop was directed toward an Innowax precolumn $(5 \mathrm{~m}$, $0.2 \mathrm{~mm}$ OD, $0.4 \mu \mathrm{m}$ film). In the first $0.5 \mathrm{~min}$ of the method, the gases coming from the precolumn were sent to the Gaspro column (Gaspro $30 \mathrm{M}, 0.32 \mathrm{~mm}$ OD). After $0.5 \mathrm{~min}$, the valve was switched and gases were sent to an Innowax column (45 m, $0.2 \mathrm{~mm} \mathrm{OD,} 0.4$ $\mu \mathrm{m})$. Products from both columns were analyzed through a FID. The Gaspro column separates $C_{1}-C_{8}$ paraffins and olefins, while the Innowax column separates oxygenates and aromatics. The error in 
carbon balance was $<3.5 \%$ in reactions using the $\mathrm{InCo}+$ beta dual-bed configuration and $<2.5 \%$ in all other cases.

$\mathrm{CO}_{2}$ conversion $\left(X_{\mathrm{CO}_{2}}, \%\right)$, selectivity to $\mathrm{CO}\left(S_{\mathrm{CO}}, \%\right)$, selectivity to product $\mathrm{C}_{x}\left(S\left(\mathrm{C}_{x}\right), \%\right)$, hydrocarbon distribution of product $\mathrm{C}_{x}$ $\left(\mathrm{HC}_{\mathrm{C}^{\prime}} \%\right)$, and the space-time yield of product $\mathrm{C}_{x}$ (STY, $\mathrm{mL} \mathrm{gat}^{-1}$ $\mathrm{h}^{-1}$ ) were defined using the formulas

$$
\begin{aligned}
& X_{\mathrm{CO}_{2}}=\left(1-\frac{C\left(\text { Inert }_{\text {blank }}\right) \cdot C\left(\mathrm{CO}_{2 \mathrm{R}}\right)}{C\left(\text { Inert }_{\mathrm{R}}\right) \cdot C\left(\mathrm{CO}_{2 \text { blank }}\right)}\right) \times 100 \\
& S_{\mathrm{CO}}=\frac{C(\mathrm{CO})}{C\left(\mathrm{CO}_{2 \text { blank }}\right)-C\left(\mathrm{CO}_{2 \mathrm{R}}\right)} \times 100 \\
& S\left(\mathrm{C}_{x}\right)=\frac{x \times C\left(\mathrm{C}_{x}\right)}{\sum_{i}\left(x \times C\left(\mathrm{C}_{x}\right)\right)+C(\mathrm{CO})} \times 100 \\
& \mathrm{HC}_{C_{x}}=\frac{S\left(\mathrm{C}_{x}\right)}{\sum_{i}\left(S\left(\mathrm{C}_{x}\right)\right)} \times 100 \\
& \mathrm{STY}=\frac{X_{\mathrm{CO}_{2}} \times S\left(\mathrm{C}_{x}\right) \times \mathrm{GHSV}_{\mathrm{CO}_{2}}}{10000}
\end{aligned}
$$

where $\mathrm{C}\left(\right.$ Inert $\left._{\text {blank }}\right), \mathrm{C}\left(\mathrm{CO}_{2 \mathrm{R}}\right), \mathrm{C}\left(\operatorname{Inert}_{\mathrm{R}}\right), \mathrm{C}\left(\mathrm{CO}_{2 \text { blank }}\right)$ are the concentrations of $\mathrm{He}$ in the blank reactor, $\mathrm{CO}_{2}$ in the outlet of the reactor, $\mathrm{He}$ in the outlet of the reactor, and $\mathrm{CO}_{2}$ in the blank reactor by GC analysis, respectively. $C\left(\mathrm{C}_{x}\right)$ is the concentration in mol \% of the hydrocarbon (olefin, paraffin, aromatic, or oxygenate) with $x$ carbon atoms in the reactor outlet as determined by GC analysis, and $i$ is the total number of analyzed products. $\mathrm{GHSV}_{\mathrm{CO}_{2}}$ refers to the gas hourly space velocity in $\mathrm{mL} \mathrm{g}_{\text {cat }}{ }^{-1} \mathrm{~h}^{-1}$ of $\mathrm{CO}_{2}$, which was kept constant across the experiments at $3000 \mathrm{~mL} \mathrm{~g}_{\mathrm{cat}}{ }^{-1} \mathrm{~h}^{-1}$.

\section{Inductively Coupled Plasma (ICP) Measurements}

The measurements were conducted with a 5100 ICP-OES instrument (Agilent) and SPS 4 Autosampler (Agilent) with Ar being used as the gas supply. Digestion was done at a maximum of $240{ }^{\circ} \mathrm{C}$ and a maximum of 35 bar using an UltraWAVE apparatus (Milestone) with a solution of aqua regia and HF. A calibration curve four plots) was built (1-10-25-100 ppm), and all samples were duplicated. Laboratory reagent blank (LRB), laboratory fortified blank (LFB), QCS, and continuing calibration verification (CCV) samples were recorded to validate the results as recommended in several standard methods. $^{38}$

\section{Nitrogen Physisorption Measurements}

The textural properties of the materials were characterized by volumetric $\mathrm{N}_{2}$ physisorption at $77 \mathrm{~K}$ using Micromeritics ASAP 2420 equipment. Prior to the physisorption experiment, the samples were dried overnight at $350{ }^{\circ} \mathrm{C}$ under vacuum $(p<2 \mu \mathrm{mHg})$. Surface areas were calculated by applying the BET (Brunauer-Emmett-Teller) equation according to Rouquerol criteria. ${ }^{39}$ To obtain the micropore area and volume, the $t$-plot method was applied within the thickness region of 3-5 $\AA$. The total pore volume of pores less than $50 \mathrm{~nm}$ was obtained at a relative pressure $p / p^{0}$ of close to 1 .

\section{X-ray Diffraction (XRD) Measurements}

XRD patterns were collected using a Bruker D8 Advance diffractometer in Bragg-Brentano geometry fitted with a copper tube operating at $40 \mathrm{kV}$ and $40 \mathrm{~mA}$ and a linear position sensitive detector (opening $2.9^{\circ}$ ). The diffractometer was configured with a $0.18^{\circ}$ diverging slit, a $2.9^{\circ}$ antiscattering slit, $2.5^{\circ}$ Soller slits, and a LYNXEYE XE-T detector. The diffractograms were acquired over the $2 \theta$ range of $5-60^{\circ}$, using a step interval of $0.037^{\circ}$ with a time step of 1 s.

\section{Fourier-Transform Infrared (FTIR) Spectroscopy} Measurements

Transmission FTIR spectroscopy using pyridine as a probe molecule was performed by using a Nicolet 6700 spectrometer equipped with an $\mathrm{MCT} / \mathrm{B}$ detector. The specimen was activated under vacuum at
$375{ }^{\circ} \mathrm{C}$ for $24 \mathrm{~h}$ to remove adsorbed species. After activation, pellets were saturated with pyridine vapor and further evacuated at $150{ }^{\circ} \mathrm{C}$ for $1 \mathrm{~h}$. Spectra were recorded in the $1000-4000 \mathrm{~cm}^{-1}$ range at 4 $\mathrm{cm}^{-1}$ resolution and coaddition of 64 scans. The amount of Brønsted (BAS) and Lewis (LAS) acid sites was derived from the bands at 1545 and $1456 \mathrm{~cm}^{-1}$ as described elsewhere ${ }^{40}$ using extinction coefficients

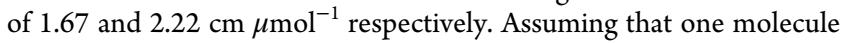
of pyridine is adsorbed on one acid site, $C_{\mathrm{BAS}}$ and $C_{\mathrm{LAS}}$ were calculated by the expressions

$$
\begin{aligned}
& C_{\mathrm{BAS}}=1.88 \times \mathrm{IA}(\mathrm{B}) \times R^{2} / W \\
& C_{\mathrm{LAS}}=1.42 \times \mathrm{IA}(\mathrm{L}) \times R^{2} / W
\end{aligned}
$$

where $C_{\mathrm{BAS}}$ and $C_{\mathrm{LAS}}$ are the concentrations of pyridine on Brønsted and Lewis acid sites, respectively $\left(\mathrm{mmol} \mathrm{g}^{-1}\right), \mathrm{IA}(\mathrm{B}$ or $\mathrm{L})$ is the integrated absorbance of the BAS or LAS band $\left(\mathrm{cm}^{-1}\right), R$ is the radius of catalyst disk $(\mathrm{cm})$, and $W$ is the mass of catalyst $(\mathrm{mg})$.

\section{X-ray Photoelectron Spectroscopy (XPS) Measurements}

The XPS experiments were performed on a Kratos Axis Ultra DLD instrument equipped with a monochromatic $\mathrm{Al} \mathrm{K} \alpha \mathrm{X}$-ray source $(h \nu=$ $1486.6 \mathrm{eV}$ ) operated at a power of $75 \mathrm{~W}$ and under UHV conditions in the range of $\sim 10^{-9}$ mbar. All spectra were recorded in hybrid mode using electrostatic and magnetic lenses and an aperture slot of $300 \mu \mathrm{m}$ $\times 700 \mu \mathrm{m}$. The survey and high-resolution spectra were acquired at fixed analyzer pass energies of 160 and $20 \mathrm{eV}$, respectively. The samples were mounted in floating mode in order to avoid differential charging. Thereafter, XPS spectra were acquired using charge neutralization.

\section{Transmission Electron Microscopy and Elemental Mapping}

High-angle annular dark-field scanning transmission electron microscopy (HAADF-STEM) analysis and energy dispersive X-ray (EDX) elemental mapping of the samples were carried out with an FEI Titan G 2 80-300 kV electron microscope operated at $300 \mathrm{kV}$.

\section{Thermogravimetric Analysis and Mass Spectrometry} (TG-MS) Measurements

Coke combustion experiments were conducted with a TGA/DSC1 Star ${ }^{\text {e }}$ System (Mettler Toledo), coupled in line with a Thermostar GSD 320 T3 (Pfeiffer Vacuum) in order to follow the evolution of the emitted $\mathrm{CO}_{2}$ signal. A spent catalyst sample (ca. $5 \mathrm{mg}$ ) was first stripped under an inert $\mathrm{N}_{2}$ stream $\left(30 \mathrm{~mL} \mathrm{~min}^{-1}\right)$ with an increase in the temperature up to $300{ }^{\circ} \mathrm{C}$ at rate of $10{ }^{\circ} \mathrm{C} \mathrm{min}-1$, and that temperature was maintained for $20 \mathrm{~min}$. Then, the sample was cooled to $100{ }^{\circ} \mathrm{C}$ and stabilized for $15 \mathrm{~min}$. Subsequently, the gas current was switched to air $\left(30 \mathrm{~mL} \mathrm{~min}^{-1}\right)$ and the temperature was increased to $600{ }^{\circ} \mathrm{C}$ at a rate of $5{ }^{\circ} \mathrm{C} \mathrm{min}^{-1}$, an isotherm of $60 \mathrm{~min}$ being maintained once that temperature was reached. Coke was quantified from the $\mathrm{CO}_{2}$ signal registered in the MS instead of the thermogravimetric signal in order to avoid any potential masking effect of the signal due to metal oxidation effects.

\section{X-ray Absorption Spectroscopy (XAS)}

Collection of Data. Conventional X-ray absorption near edge structure (XANES) and extended X-ray absorption fine structure (EXAFS) spectra were measured at the Co and $\mathrm{Zn} \mathrm{K}$ edge, from 150 $\mathrm{eV}$ before the edge to $1000 \mathrm{eV}$ above the edge, on the SAMBA beamline (spectroscopy applied to material based on absorption) at the French National Synchrotron Facility (SOLEIL) in Paris, France. The details of the beamline and its optical devices have been described by Belin et al. ${ }^{41}$ The beamline was equipped with a sagittally focusing $\mathrm{Si}(220)$ monochromator. The presence of two Pdcoated mirrors ensured the rejection of the harmonics to better than $0.1 \%$ : i.e., the intensity of the harmonics was less than $0.1 \%$ of the intensity of the fundamental X-rays. The incident $\left(I_{0}\right)$ and transmitted $\left(I_{1}\right)$ intensities were measured by ionization chambers. The fluorescence photons were measured by a Canberra 35-element Ge solid-state detector. The energy was calibrated by measuring the 
spectrum of a reference metallic foil (first maxima of the derivatives being set at 9659 and $7709 \mathrm{eV}$ for $\mathrm{Zn}$ and Co, respectively).

The characterization of catalysts under real high-temperature reaction conditions was performed using a custom-made setup developed at the Neel Institute in Grenoble for the study of catalysts under pressures of up to 1000 bar (Figure S9). This new setup was based on previously validated developments: a catalytic reactor and an autoclave. ${ }^{42,43}$ Briefly, the cell was a plug-flow reactor made of a vitreous carbon tube, which allowed most of the X-ray beam to be transmitted. The heating element design consisted of sliding the carbon reactor in a molybdenum tube that was heated to the experimental temperature with a resistive Mo metallic wire. An automated gas distribution system was used to deliver a mixture of gases at the right pressure while the conversion of reactants and the formation of products were monitored online by mass spectrometry. For the InCo + beta catalyst studied in a mixed-bed configuration, 50 $\mathrm{mg}$ of beta catalyst and $50 \mathrm{mg}$ of InCo catalyst were mixed in a mortar before being sandwiched in the reactor between $15 \mathrm{mg}$ (bottom) and $2 \mathrm{mg}$ (top) of quartz wool. For the InCo $+\mathrm{Zn}$-beta catalyst studied in a dual-bed configuration, $15 \mathrm{mg}$ of quartz wool, $50 \mathrm{mg}$ of $\mathrm{Zn}$-beta catalyst, $2 \mathrm{mg}$ of quartz wool, $50 \mathrm{mg}$ of InCo catalyst, and $2 \mathrm{mg}$ of quartz wool were successively introduced in the reactor. Since SAMBA is a focused beamline ( $\sim 200 \mu \mathrm{m}$ on vertical axis), we could independently analyze each part of the fixed bed. Note that we did not observe any migration of Co atoms on to the zeolite bed at the end of the reaction (as evaluated by X-ray fluorescence).

Co and $\mathrm{Zn} \mathrm{K}$ edge XAS spectra were recorded in air in order to characterize the initial state of the catalyst and then under $\mathrm{He}(100$ $\mathrm{mL} \mathrm{min}^{-1}$ ) at room temperature. Then, the cell was heated to $300{ }^{\circ} \mathrm{C}$ at a rate of $5{ }^{\circ} \mathrm{C} \mathrm{min}{ }^{-1}$ under an He flow, dehydrating the sample. The total pressure was further raised to 50 bar. During this pretreatment, XANES spectra were recorded continuously to observe the change in the metal oxidation state and EXAFS spectra were recorded at the end. Then, $\mathrm{CO}_{2}$ hydrogenation was carried out by introducing $50 \mathrm{~mL}$ $\min ^{-1}$ of the reaction mixture $\left(20 \% \mathrm{CO}_{2}: 79 \% \mathrm{H}_{2}: 1 \% \mathrm{Ar}\right)$ while the pressure was kept at 50 bar. The reaction was stopped after $20 \mathrm{~h}$, and the last EXAFS spectra were merged to compare the final states of the catalysts.

Processing of Spectra. All XAS data were processed using the FASTOSH package. ${ }^{44}$ The XANES and EXAFS spectra were obtained after performing standard procedures for pre-edge subtraction, normalization, polynomial removal, and wavevector conversion.

EXAFS Curve Fitting. EXAFS data were analyzed using the Demeter package, a graphical interface to the AUTOBK and IFEFFIT code. ${ }^{45}$ First-shell analyses were conducted within a $k$ range of 3.0-11 $\AA^{-1}$ with a Hanning window $(\mathrm{dk}=1)$ and an $R$ range of 1.0-2.2 using a single $\mathrm{Zn}-\mathrm{O}$ scattering path calculated with $\mathrm{FEFF}^{46}$ using the $\mathrm{ZnO}$ crystal structure. ${ }^{47}$ The parametrization of the fit was as follows: a single shift of energy was used, amplitudes were adjusted by a single amplitude reduction factor $\left(S_{0}^{2}\right)$, the variation of distances for each scattering paths was adjusted by a single $\Delta R$ parameter, and the disorder was fitted with one mean relative square displacement parameter. The fitting performed on the $\mathrm{ZnO}$ standard allowed the determination of $S_{0}{ }^{2}$ equal to $0.87 \pm 0.09$ ( $R$ factor: $\left.0.1 \%\right)$ and was further injected in the fitting of all further EXAFS spectra to allow the determination of the coordination number for the $\mathrm{Zn}$-beta catalyst under various experimental conditions (Table S2 and Figure S19).

Reverse Monte Carlo Calculations. The extended X-ray absorption fine structure (EXAFS) $\chi(k) k^{2}$ of the Zn-beta catalyst in its dehydrated state was analyzed by reverse Monte Carlo calculations coupled with an evolutionary algorithm approach (RMC/EA), as implemented by Timoshenko et al. within the EvAX code. ${ }^{48}$ Initial structural models for RMC/EA calculations were all taken from previous DFT geometry optimizations of $\mathrm{Zn}$ structural models. Supercells were sized using periodic boundary conditions in order to include between 100 and 200 absorber atoms. RMC/EA calculations were simultaneously performed for 64 atomic configurations. The configuration-averaged EXAFS spectra were calculated using the $a b$ initio self-consistent real space multiple-scattering (MS) FEFF8.5L code. ${ }^{49}$ The amplitude reduction factor $S_{0}{ }^{2}$ was equal to 0.87 . After investigating the effect of the maximum allowable displacement of atoms, we found out that allowing a large degree of freedom was hindering the discrimination among the various structural models. Hence, we intentionally reduced the maximum allowable displacement of atoms out of their initial positions to $0.2 \AA$. This small value still allowed us to take into account static and dynamical disorder while strictly enforcing the initial model geometry, thus enhancing differences between all structural candidates. A comparison between the experimental and calculated EXAFS spectra was performed using the Morlet wavelet transform in the $k$-space range from 3.5 to $12.2 \AA$ and in the $R$-space range from 0.7 to $6 \AA$. Wavelet transform provides a two-dimensional representation of the EXAFS spectrum in $k$ and $R$ spaces simultaneously that helps in the fitting procedure. ${ }^{50}$ The metric $\xi_{k, R}$ is used to assess the fit quality by comparing the difference between spectra

$$
\xi_{k, R}=\frac{\left\|w_{\text {cal }}(R, k)-w_{\text {exp }}(R, k)\right\|}{\left\|w_{\exp }(R, k)\right\|}
$$

where $w_{\text {cal }}$ and $w_{\exp }$ are the Morlet wavelet transforms of calculated and experimental EXAFS spectra. In the main text, only the best structural models are presented: i.e., those with a $\xi_{k, R}$ value of less than 0.1

Simulation of XANES Spectra. Ab initio simulations of the XANES spectra for the $\mathrm{Zn} \mathrm{K}$ edge were performed using the FDMNES package. The FDMNES code features monoelectronic calculations, which were carried out in real space with a HedinLundqvist exchange-correlation potential and using clusters built around each nonequivalent absorbing atom. Standard crystal structures (retrieved from the "Inorganic Crystal Structure Database", FIZ Karlsruhe) were used as inputs. The finite-difference method (FDM) implemented in the FDMNES code was used, since the latter is a full-potential method that introduces no approximation on the shape of the potential, which is particularly important in dealing with highly distorted structures. ${ }^{51}$ The current implementation at KAUST of the most recent FDMNES version with the MUMPS solver allows FDM calculations with a $7 \AA$ cluster radius, which was not possible when the built-in solver was used because of the required memory footprint and the CPU runtime. ${ }^{52}$ Quadrupolar transitions were included in the calculation. To take into account the core-hole lifetime and other multielectronic phenomena occurring in the absorption process, a convolution procedure was applied to all calculated spectra presented in this work. At the Fermi level, the Lorentzian (fwhm) width was set to the natural width of the core-hole and was equal to $1.67 \mathrm{eV}$. $^{53}$ At higher photoelectron energies, the plasmon collective interactions increase the Lorentzian width to 5-10 eV.

\section{RESULTS AND DISCUSSION}

\section{Influence of the Catalyst Bed Configuration}

In the course of this study, we have observed that the product distribution is markedly different depending on the catalytic configuration used. Coupling the InCo catalyst and unmodified beta zeolite in a dual-bed configuration at $300{ }^{\circ} \mathrm{C}$ leads to a fast deactivation of the zeolite $(\sim 4-5 \mathrm{~h}$, Figure $1 \mathrm{~b}$ and Figure S1), with methanol and DME being the chief products in the hydrocarbon fraction after deactivation (Figure S1). Before deactivation, the products in the hydrocarbon fraction mainly consisted of paraffins (chiefly isobutane with ca. $45 \%$ selectivity among the hydrocarbons; Figure 1a). Among the light paraffins $\left(\mathrm{C}_{1}-\mathrm{C}_{3}\right)$, methane was the main product observed $(\sim 6 \%$ hydrocarbon selectivity). Olefinic products were observed in a relatively low amount with their total selectivity in the hydrocarbon fraction $\left(\mathrm{C}_{2}-\mathrm{C}_{7}\right.$ olefins $)$ being approximately $7 \%$. Other hydrocarbon products observed included $\mathrm{C}_{5}-\mathrm{C}_{7}$ paraffins. Among the paraffinic products $\left(\mathrm{C}_{4}-\mathrm{C}_{7}\right)$, it was observed that branched isomers (denoted as iso- $\mathrm{C}_{\mathrm{N}}$ in Figure 

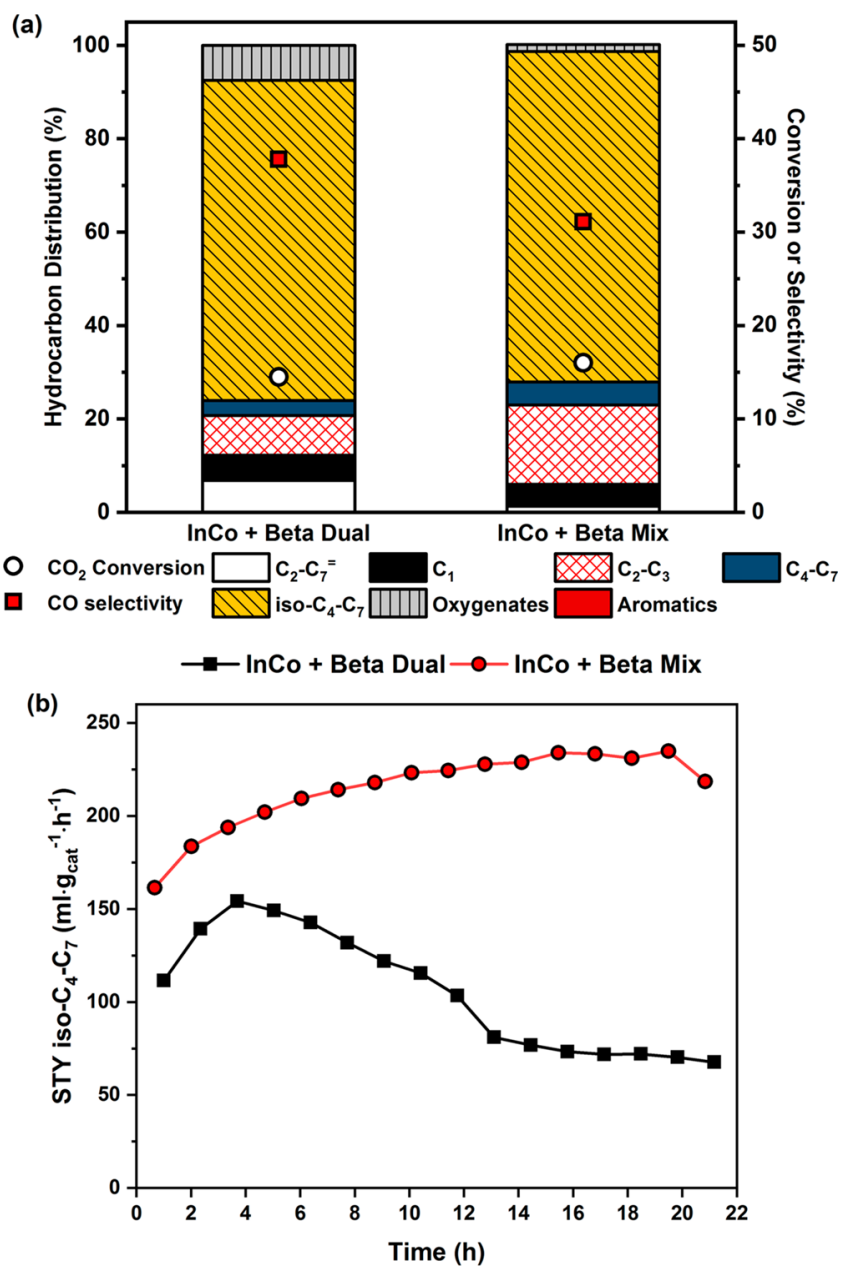

Figure 1. Catalytic performance of the multifunctional InCo + Beta in a fixed-bed system. (a) Hydrocarbon distribution reported at $\sim 5 \mathrm{~h}$ time on stream and overall $\mathrm{CO}_{2}$ conversion and $\mathrm{CO}$ selectivity on a carbon mole basis. (b) Isoparaffin STY comparison of the two catalyst bed configurations. "Oxygenates" denotes the cumulative proportion of methanol and dimethyl ether in the hydrocarbon fraction of products. " $\mathrm{C}_{N}$ " and "iso- $\mathrm{C}_{N}$ " denotes the proportion of linear and branched isomers of the paraffins with carbon number $N$, respectively, while " $\mathrm{C}_{N}$ "” denotes the proportion of olefins with carbon number $N$ in the hydrocarbon fraction. In the case of olefins, both linear and branched isomers have been summed up. "Aromatics" denotes the cumulative proportion of aromatics (ranging from benzene to $\mathrm{C}_{10}$ aromatics) in the hydrocarbon fraction.

1) were present in much higher quantities in comparison to their linear counterparts, adding up to a total of approximately $70 \%$ of the total hydrocarbons formed. The $\mathrm{CO}_{2}$ conversion was, in general, a feature of the InCo catalyst being close to $15 \%$ on average except when the catalyst was used in a mixedbed configuration with $\mathrm{Zn}$-beta (vide infra). The CO selectivity was approximately $37 \%$ for the dual-bed configuration.

On the other hand, the use of a mixed-bed configuration led to a considerable enhancement in the stability of the multifunctional catalyst with significantly slower deactivation being observed within a $22 \mathrm{~h}$ time frame (as denoted by the STY evolution with respect to time in Figure $1 \mathrm{~b}$ and in Figure S1). The product distribution was in general similar to the that of the dual-bed configuration before its deactivation with respect to isoparaffins. However, higher quantities of light paraffins $\left(\mathrm{C}_{1}-\mathrm{C}_{3}\right)$ and lower quantities of olefins were produced in the mixed-bed configuration in comparison to the dual-bed configuration. It should be emphasized here that in this study, for the most part, deactivation of the multifunctional catalyst refers to the zeolite and not to the InCo catalyst. We have previously observed that the InCo catalyst remains stable for at least $150 \mathrm{~h} .{ }^{35}$ Upon encountering the Brønsted acidic sites of the zeolite, the methanol produced via the InCo catalyst initially gives rise to olefinic species according to the classical MTH mechanism. These species can immediately oligomerize and aromatize to form the so-called "hydrocarbon pool" which, depending on the nature of the zeolite, gives rise to various products. ${ }^{54,55}$

It has generally been observed that zeolites with large pores and/or large cages (e.g., beta and SAPO-34) tend to deactivate more quickly during $\mathrm{MTH}$ because of the presence of heavier polyaromatic species in the hydrocarbon pool. ${ }^{55,56}$ This is possibly the reason for the fast deactivation of the beta zeolite in the case of the dual-bed configuration. However, in the case of the mixed-bed configuration, the close proximity of the InCo catalyst to the zeolite acid sites allows for the activation of $\mathrm{H}_{2}$ (presumably by the Co sites), which can react with the olefins generated over the zeolite. This is analogous to observations made by Ruddy et al., ${ }^{33}$ where a physical mixture of $\mathrm{Cu} / \mathrm{SiO}_{2}$ and zeolite beta enhanced the hydrocarbon production from DME in the presence of $\mathrm{H}_{2}$. They postulated that the metallic $\mathrm{Cu}$ present could be responsible for activating $\mathrm{H}_{2}$. The hydrogen activation (and subsequent hydrogenation) role of the InCo catalyst is further supported by ethylene hydrogenation experiments carried out over the standalone InCo catalyst (Figure S10), which resulted in $\sim 100 \%$ conversion of ethylene to ethane at the beginning. Since Co is well-known for its activity as a hydrogenation catalyst ${ }^{57}$ and since we have an excess of hydrogen in our feed, the olefins chiefly end up being hydrogenated to paraffins instead of forming aromatics. ${ }^{58}$ This also accounts for the much lower fraction of olefins in the hydrocarbon products (approximately $1 \%)$ in comparison to the dual-bed configuration. Furthermore, it is seen that the paraffins formed are mostly branched in nature (i.e., isoparaffins) due to the well-known tendency of the beta zeolite to catalyze the isomerization of hydrocarbons due to its unique pore structure ${ }^{59}$ and/or its propensity to form branched alkanes from methanol/DME. ${ }^{60}$ Interestingly, the $\mathrm{CO}$ selectivity in this configuration was reduced considerably, being ca. $6 \%$ lower in comparison to the dual bed configuration. This can possibly be attributed to enhanced $\mathrm{CO}$ incorporation in the zeolite, as observed in our previous studies. ${ }^{61,62}$ The olefins produced from methanol can be coincorporated with $\mathrm{CO}$ into the zeolite and give rise to more light olefins. These light olefins in turn can be hydrogenated over the InCo (possibly by the Co sites). This is supported by the fact that the light paraffin fraction, particularly ethane and propane, is higher in the case of the mixed-bed configuration in comparison to the dual-bed configuration (see Figure S8). Once again, a similar observation had been made by Ruddy et al., ${ }^{33}$ and they reported that a physical mixture of $\mathrm{Cu} / \mathrm{SiO}_{2}$ and zeolite beta increases the paraffin/olefin ratio for $\mathrm{C}_{2}-\mathrm{C}_{3}$ hydrocarbons during DME homologation in the presence of $\mathrm{H}_{2}$.

\section{Zeolite Modification to Enhance the Production of Isoparaffins}

As stated before, Ruddy et al. ${ }^{33,34}$ recently demonstrated the possibility of producing isoparaffins from DME in the presence 
of $\mathrm{H}_{2}$ using a $\mathrm{Cu}$-modified zeolite beta catalyst. The main product in this case was isobutane, which can easily be converted to the important gasoline additive isooctane, by carrying out alkylation of isobutene with isobutane. ${ }^{63,64}$ They revealed that it is even possible to produce 2,2,3trimethylbutane (also known as triptane), which can be used as an antiknock additive in aviation fuels. Thus, we reasoned that another first-row transition metal close to $\mathrm{Cu}$ could also be effective, which proved to be true in our study. Therefore, we modified beta zeolite with $\mathrm{Zn}$ via incipient wetness impregnation (referred to as Zn-beta), which led to an improvement in the yield of isoparaffins (especially $\mathrm{C}_{5}-\mathrm{C}_{7}$ isoparaffins) in comparison to the mixed-bed configuration of InCo + beta. Other studies have also been carried out where ZSM-5 was modified by $\mathrm{Zn}$ and led to the production of isoparaffin-rich gasoline from DME. ${ }^{65-68}$

The product distribution outcome for Zn-beta, however, runs counter to that of zeolite beta, as the dual-bed configuration is more stable than the mixed-bed configuration and leads to the desired products (Figure 2 and Figure S1). The deactivation of the catalyst in this configuration (indicated by the increase in the oxygenate fraction of hydrocarbon products) is much slower in the former case than in the latter.
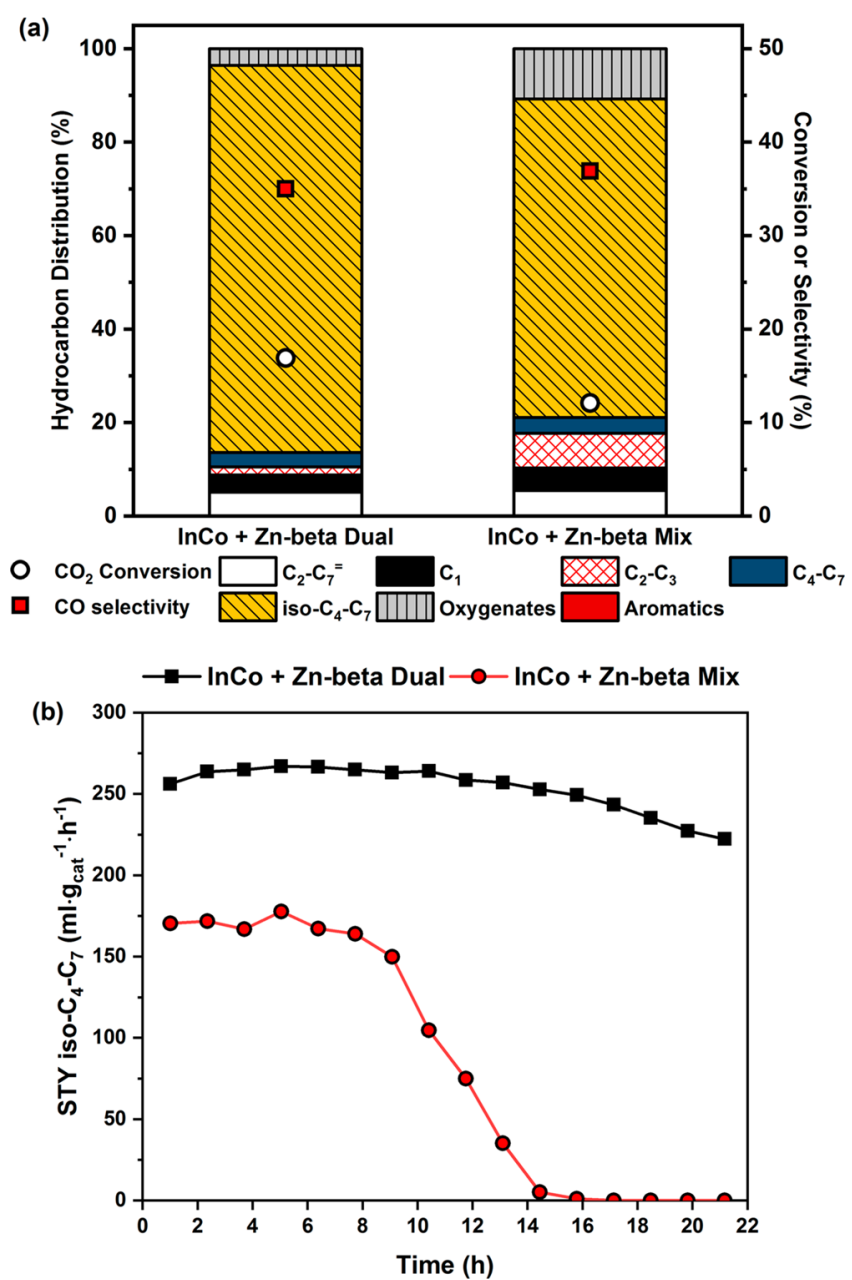

Figure 2. Catalytic performance of the multifunctional $\mathrm{InCo}+\mathrm{Zn}$ beta in a fixed-bed system. (a) Hydrocarbon distribution reported at $\sim 5 \mathrm{~h}$ time on stream and overall $\mathrm{CO}_{2}$ conversion and $\mathrm{CO}$ selectivity on a carbon mole basis. (b) Isoparaffin STY comparison of the two catalyst bed configurations.
In particular, the olefin fraction in this case is approximately $5 \%$ and the total isoparaffin fraction initially accounts for almost $85 \%$ of the total hydrocarbons. To the best of our knowledge, this is among the highest values reported so far for isoparaffin production from $\mathrm{CO}_{2}$ (Table $\mathrm{S} 1$ ). This value is also quite a bit higher than that observed for the $\mathrm{InCo}+$ beta mixed-bed configuration $(\sim 70 \%)$. Furthermore, while the InCo + beta mixed-bed configuration only has a hydrocarbon selectivity of $\sim 21 \%$ toward the more valuable iso- $\mathrm{C}_{5}-\mathrm{C}_{7}$ fraction, the InCo $+\mathrm{Zn}$-beta dual-bed configuration enhances the hydrocarbon selectivity to this fraction more than 1.5 times, being ca. $36 \%$. Moreover, the production of less valuable light paraffins $\left(\mathrm{C}_{1}-\mathrm{C}_{3}\right)$ is also greatly inhibited when the InCo $+\mathrm{Zn}$-beta dual-bed configuration is used in comparison to the InCo + beta mixed-bed configuration ( $\sim 5 \%$ vs $\sim 22 \%)$. On the other hand, when a mixed-bed configuration is used for InCo + Zn-beta, it appears that the two components have a dysergistic effect on each other, leading to lower activity (the conversion of $\mathrm{CO}_{2}$ is $\sim 12 \%$ as opposed to $\sim 16 \%$ in the case of the dualbed configuration), a lower isoparaffin yield, and a lower stability of the overall catalytic system. We speculate that $\mathrm{Zn}$ migration occurs under the reaction conditions from $\mathrm{Zn}$-beta to InCo when the InCo $+\mathrm{Zn}$-beta mixed-bed configuration is used. The observation of $\mathrm{Zn}$ migration in a mixed-bed catalyst under $\mathrm{CO}_{2}$ hydrogenation conditions has recently been reported by Wang et al. ${ }^{69}$ In order to simulate the proximity of $\mathrm{Zn}$ to InCo (or possible $\mathrm{Zn}$ migration to $\mathrm{InCo}$ ) when the InCo $+\mathrm{Zn}$-beta mixed-bed configuration is used, we prepared a control sample of InCo impregnated with $\mathrm{Zn}$ (denoted as InCo- $\mathrm{Zn}$ ) and tested its performance for $\mathrm{CO}_{2}$ hydrogenation (Figure S11). A significant decrease in $\mathrm{CO}_{2}$ conversion was observed for InCo- $\mathrm{Zn}$ in comparison to standalone InCo. This is analogous to the decrease in $\mathrm{CO}_{2}$ conversion observed when InCo $+\mathrm{Zn}$-beta (dual bed) and InCo $+\mathrm{Zn}$-beta (mixed bed) are compared, thus providing evidence for the dysergistic effect of $\mathrm{Zn}$ on InCo brought on by their close proximity in the mixed-bed configuration.

\section{Zeolite Characterization: Unraveling the Status of Zn}

A comprehensive suite of techniques was applied in order to characterize both zeolite beta and Zn-beta. First, on comparison of the XRD patterns of beta and $\mathrm{Zn}$-beta (Figure S2), we observed that they were essentially similar in nature with some slight distortion of the peaks in the latter case. This $\mathrm{XRD}$ pattern is consistent with beta containing approximately $44 \%$ of polymorph $\mathrm{A}$ and $56 \%$ of polymorph $\mathrm{B}$, with the content of polymorph $\mathrm{C}$ being negligible. ${ }^{70}$

The textural properties of the two samples were also compared via $\mathrm{N}_{2}$ adsorption at $77 \mathrm{~K}$ (Figure S3 and Table 2), and predictably, there was a drop in the surface area and pore volume when beta was impregnated with $\mathrm{Zn}$. Furthermore, an acidity characterization was carried out via FTIR using pyridine as a probe molecule in order to identify the effect of $\mathrm{Zn}$ on the zeolite acidity. The results are presented in Figure S7 and Table 2. As could be expected, the incorporation of $\mathrm{Zn}$ in the beta zeolite led to a decrease in the number of Brønsted acid sites and an increase in the quantity of Lewis acid sites. $^{65,66}$

XPS analysis of both fresh and spent $\mathrm{Zn}$-beta revealed no major changes in the state of $\mathrm{Zn}$, as can be observed in Figure S5. The spectra were commensurate with that of the standard $\mathrm{ZnO}$ state of $\mathrm{Zn}$. A HAADF-STEM analysis of fresh $\mathrm{Zn}$-beta showed a homogeneous distribution of $\mathrm{Zn}$ in the zeolite 
Table 2. Acidic and Textural Properties of the Unmodified and Modified Zeolites

$\begin{array}{lcccccccc}\text { Sample } & \begin{array}{c}\text { Zn loading } \\ (\text { wt } \%)\end{array} & S_{\mathrm{BET}}{ }^{b}\left(\mathrm{~m}^{2} \mathrm{~g}^{-1}\right) & S_{\text {meso }}{ }^{c}\left(\mathrm{~m}^{2} \mathrm{~g}^{-1}\right) & S_{\text {micro }}{ }^{c}\left(\mathrm{~m}^{2} \mathrm{~g}^{-1}\right) & V_{\text {total }}{ }^{c}\left(\mathrm{~cm}^{3} \mathrm{~g}^{-1}\right) & V_{\text {micro }}{ }^{c}\left(\mathrm{~cm}^{3} \mathrm{~g}^{-1}\right) & C_{\mathrm{BAS}}{ }^{d}\left(\mu \mathrm{mol} \mathrm{g}^{-1}\right) & C_{\mathrm{LAS}}{ }^{d}\left(\mu \mathrm{mol} \mathrm{g}^{-1}\right) \\ \text { beta } & & 756 & 256 & 500 & 0.42 & 0.20 & 232 & 246 \\ \text { Zn-beta } & 4.43 & 518 & 157 & 361 & 0.29 & 0.15 & 97\end{array}$

${ }^{a}$ By ICP-OES. ${ }^{b}$ By $\mathrm{N}_{2}$ adsorption using the BET method. ${ }^{c}$ By $\mathrm{N}_{2}$ adsorption using the $t$-plot method. ${ }^{d}$ By FT-IR using pyridine as a probe molecule.
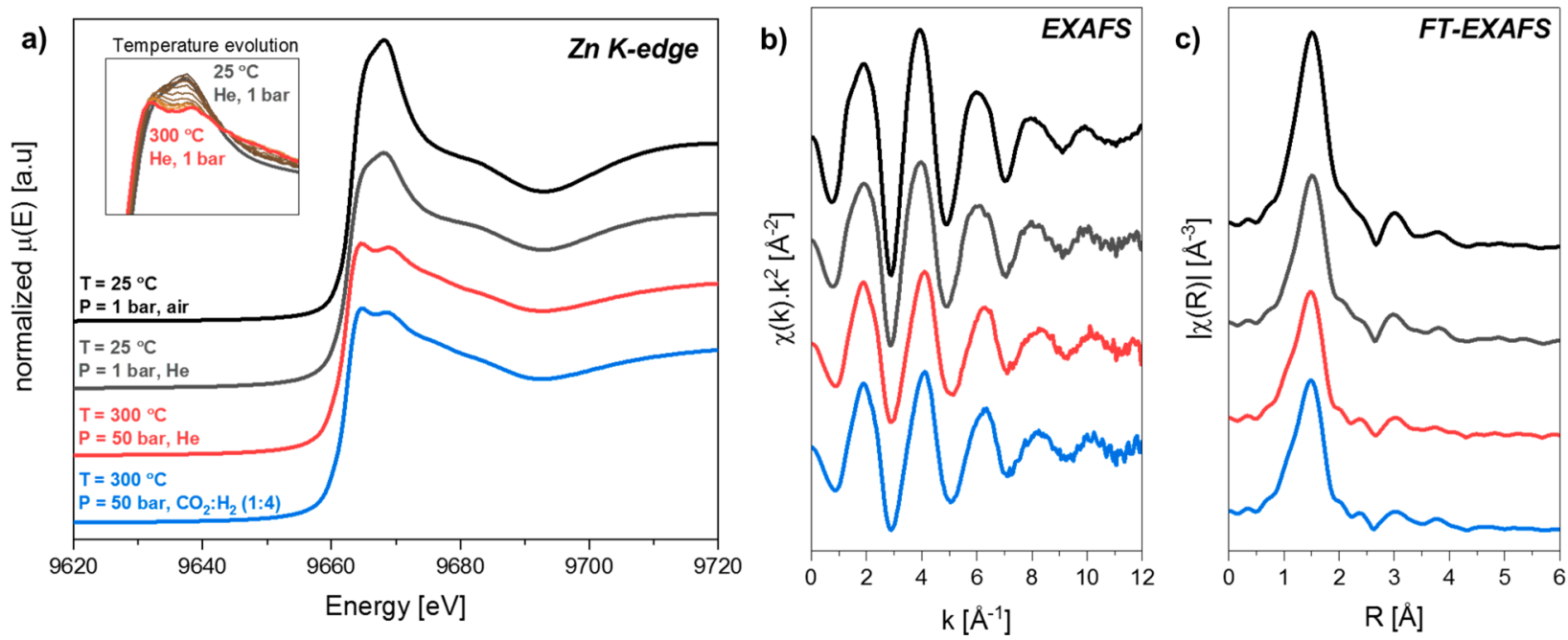

Figure 3. Evolution of the operando Zn K edge (a) XANES, (b) EXAFS, (c) FT-EXAFS spectra of the InCo + Zn-beta (dual bed) catalyst starting from the as-synthesized state $\left(T=25{ }^{\circ} \mathrm{C}, P=1 \mathrm{bar}\right.$, air $)$, after dehydration under $\mathrm{He}\left(T=25-300{ }^{\circ} \mathrm{C}, P=1-50 \mathrm{bar}\right.$, pure $\left.\mathrm{He}\right)$, and after $20 \mathrm{~h}$ of $\mathrm{CO}_{2}$ hydrogenation $\left(\mathrm{T}=300^{\circ} \mathrm{C}, \mathrm{P}=50 \mathrm{bar}, \mathrm{CO}_{2}: \mathrm{H}_{2}=1: 4\right)$.

(Figure S6). The mapping of the spent Zn-beta after $22 \mathrm{~h}$ of reaction in the dual-bed configuration at $300{ }^{\circ} \mathrm{C}$ revealed no appreciable sintering of the $\mathrm{Zn}$ particles, with similar mapping profiles in both cases. Hence, catalyst deactivation can predominantly be attributed to coke formation.

Therefore, in order to characterize the nature of the coke deposited on the zeolite in the dual-bed configuration, a TGMS analysis was carried out on the spent zeolites after $22 \mathrm{~h}$ of reaction (Figure S4). From the normalized temperatureprogrammed oxidation (TPO) profile curves $\left(\mathrm{dCO}_{2} / \mathrm{d} t\right)$, it was observed that using the Zn-beta catalyst led to the formation of a more saturated coke, the combustion rate of which reaches a maximum value at $470{ }^{\circ} \mathrm{C}$. On the other hand, the combustion of the coke formed using zeolite beta occurs faster than that for the $\mathrm{Zn}$-beta, with a maximum combustion rate at $427{ }^{\circ} \mathrm{C}$, thus indicating a lighter and less evolved nature of the formed coke. In addition, the curves also indicate a significantly higher amount of coke being formed with the $\mathrm{Zn}$ beta catalyst $\left(47.3 \mu \mathrm{g}_{\mathrm{CO}_{2}} \mathrm{~g}_{\text {cat }}{ }^{-1}\right.$ vs $3.7 \mu \mathrm{g}_{\mathrm{CO}_{2}} \mathrm{~g}_{\mathrm{cat}}{ }^{-1}$ for zeolite beta). These observations are in agreement with the heavier products formed using the Zn-beta catalyst (Figure 2), which have a pivotal role acting as intermediates and coke precursors in the conversion of methanol. The presence of high yields of hydrocarbons through the whole reaction is another key factor for enhanced coke formation using the Zn-beta catalyst in comparison to the beta catalyst. In the case of the plain beta (Figure 1) the yields of hydrocarbons present a pronounced decrease after $\sim 4 \mathrm{~h}$ on stream, hence also partially preventing further formation and growth of coke structures over time.

To get further insight into the status of $\mathrm{Zn}$ under the reaction conditions, we monitored by operando X-ray absorption spectroscopy (XAS, at the SAMBA beamline ${ }^{41}$ of the SOLEIL synchrotron) the dehydration from room temperature (RT) to $300{ }^{\circ} \mathrm{C}$ of the $\mathrm{InCo}+$ beta (mixed bed) and $\mathrm{InCo}+\mathrm{Zn}$-beta (dual bed) catalysts, followed by their subsequent evolution during $\mathrm{CO}_{2}$ hydrogenation reaction for a total of $20 \mathrm{~h}$. To enable such a high-pressure study, a plug-flow reactor was specifically designed (cf. Figure S9 in the Supporting Information). The aim of this study was 3-fold: (i) to perform a structural and operando characterization of the InCo catalyst as a follow-up of our previous ex situ investigations, $^{35,71}$ (ii) to pinpoint any difference in the structure of the InCo catalyst between the dual-bed and the mixed-bed configuration, and (iii) to characterize the local structural order around $\mathrm{Zn}$ atoms in the $\mathrm{Zn}$-beta catalyst. Hence, Co $\mathrm{K}$ edge spectra were recorded for $\mathrm{InCo}+$ beta (mixed bed) and InCo $+\mathrm{Zn}$-beta (dual bed) catalysts and the experiment was repeated for the InCo $+\mathrm{Zn}$-beta catalyst for the acquisition of the $\mathrm{Zn} \mathrm{K}$ edge spectra. The results and the corresponding discussion for the Co $\mathrm{K}$ edge spectra can be found in the Supporting Information.

$\mathrm{XAS}$ at the $\mathrm{Zn} \mathrm{K}$ edge was used to investigate the nature and coordination properties of $\mathrm{Zn}$ species in the $\mathrm{Zn}$-beta catalyst under the relevant operating conditions. Figure 3 shows the XANES and FT-EXAFS spectra for a Zn-beta catalyst in its hydrated state (RT, in air and $\mathrm{He}$ ), after complete dehydration at $300{ }^{\circ} \mathrm{C}$ using a $\mathrm{He}$ pressure of $50 \mathrm{bar}$ and after $20 \mathrm{~h}$ of $\mathrm{CO}_{2}$ hydrogenation $\left(T=300{ }^{\circ} \mathrm{C}, P=50\right.$ bar, $\left.\mathrm{CO}_{2}: \mathrm{H}_{2}=1: 4\right)$. With the as-synthesized Zn-beta catalyst (in air), its XANES spectrum shows a shape similar to those recorded for a $\mathrm{Zn}\left(\mathrm{NO}_{3}\right)_{2} \cdot 6 \mathrm{H}_{2} \mathrm{O}$ solid or its solution as a $\left[\mathrm{Zn}\left(\mathrm{H}_{2} \mathrm{O}\right)_{6}\right]^{2+}$ complex (Figure S22). ${ }^{72,73}$ The most characteristic feature is the white line at $9668 \mathrm{eV}$ typical of $\mathrm{Zn}^{2+}$ cations in a quasioctahedral coordination. However, a first-shell quantitative 
analysis of the EXAFS data finds $5.2 \pm 0.3$ oxygen atoms bonded to $\mathrm{Zn}$ at a $2.005 \pm 0.006 \AA$ distance (Figure S23 and Table S2), which explains the weaker intensity of the white line in comparison to $\mathrm{Zn}$ standards having a well-defined octahedral geometry. Furthermore, the FT-EXAFS spectra do not show any strong peaks in the range of $\sim 2-6 \AA$ that are typical of a crystalline $\mathrm{ZnO}$ phase (Figure 3 and Figure S21). This fact already suggests that the initial structure of the $\mathrm{Zn}$ beta catalyst could involve either isolated $\mathrm{Zn}^{2+}$ cations bonded to the BEA framework and/or small $\mathrm{ZnO}$ clusters with considerable structural disorder.

Switching the atmosphere to pure He further decreases the intensity of the white line and the intensity of the first-shell EXAFS peak, which is quantified subsequently by a lower number of oxygen atoms (3.6 \pm 0.2$)$. Increasing the temperature to $300{ }^{\circ} \mathrm{C}$ and raising the He pressure to 50 bar further decreases this coordination number to $2.66 \pm 0.09$ at a slightly shorter bond distance of $1.959 \pm 0.004 \AA$ (Figure S23 and Table S2). Those results were previously interpreted by Iglesia et al. with a $\mathrm{Zn} / \mathrm{H}-\mathrm{ZSM} 5$ catalyst as the mark of a dehydration process, reflecting a weak adsorption of water onto $\mathrm{Zn}$ species. ${ }^{74}$ The absorption threshold defined as the first maximum of the derivative also decreases from $9663.3 \mathrm{eV}$ in the hydrated state to $9662.5 \mathrm{eV}$ in the activated state. The locations of the absorption edges for all experimental conditions are very close to those of bulk $\mathrm{ZnO}$, indicating that $\mathrm{Zn}$ remains predominantly in its $+\mathrm{II}$ state (cf. $E_{0}=9661.8$ $\mathrm{eV}$ for $\mathrm{ZnO}$ and $E_{0}=9658.9 \mathrm{eV}$ for $\mathrm{Zn}^{0}$ ). During dehydration, the most striking changes actually lie in the overall shape of the XANES spectrum. Indeed, the decrease in the white-line intensity during heating is also accompanied by a clear split into two post-edge peaks positioned at 9664.7 and $9668.7 \mathrm{eV}$ (inset of Figure 3), suggesting marked coordination changes for the $\mathrm{Zn}$ species. Those two features appear completely distinct from the main resonances of bulk $\mathrm{ZnO}$ in terms of energy positions and intensities (Figure S22). Submitting the catalyst to $\mathrm{CO}_{2}$ hydrogenation conditions has a negligible effect on the resulting XANES and EXAFS spectra (Figure 3, Figure S23, and Table S2). This implies that there are no significant structural changes of the $\mathrm{Zn}$ species on going from the dehydrated state to the state under the reaction conditions.

In the following part, we will attempt to progress in the structural analysis of the $\mathrm{Zn}$ active sites. Prior to a detailed discussion of the analysis, it is worthwhile to present a short state of the art of XAS characterization of $\mathrm{Zn}$-modified zeolites. $^{73-80}$ Zn-modified zeolites have been prepared by various methods, including chemical vapor deposition of dimethylzinc/zinc vapor (CVD), incipient wetness impregnation (IWI), and ion exchange methods (IE). Most of the XAS studies have been dedicated to ZSM-5 as a host with few reports dealing with beta zeolite. The common wisdom is that in materials with low $\mathrm{Zn}$ content and low $\mathrm{Si} / \mathrm{Al}$ ratio, monomeric $\mathrm{Zn}^{2+}$ cations are stabilized on cation-exchange sites via coordination to oxygen atoms in the proximity of two framework aluminum atoms $(\mathrm{Zn} / \mathrm{Al}=0.5)$. With higher $\mathrm{Zn}$ loadings and an intermediate $\mathrm{Si} / \mathrm{Al}$ ratio, $\mathrm{Zn}-\mathrm{OH}$ species would form instead (one $\mathrm{Zn}-\mathrm{OH}$ species interacting with one cation-exchange site, $\mathrm{Zn} / \mathrm{Al}=1){ }^{73}$ Possibly, applying high temperature to the sample may trigger the condensation of two nearby $\mathrm{Zn}-\mathrm{OH}$ species to form oxygen-bridged $\mathrm{Zn}-\mathrm{O}-\mathrm{Zn}$ species. There is also one interesting outlier that establishes the stabilization of an unusual $+\mathrm{I}$ oxidation state as $\left[\mathrm{Zn}_{2}\right]^{2+}$ dimeric species immobilized into the pore system of $\mathrm{ZSM}-5(\mathrm{Si} / \mathrm{Al}=$
11.9). ${ }^{77}$ Finally, the research teams from the Boreskov Institute of Catalysis and the Eindhoven University of Technology have highlighted the key role of multinuclear $\mathrm{Zn}_{n} \mathrm{O}_{m}$ clusters from overexchanged zeolites $(\mathrm{Zn} / \mathrm{Al} \gg 1)$ in dehydrogenation and aromatization reactions. $^{75,76}$ Evidently, a mixture of all those $\mathrm{Zn}$ species is also possible, depending on the distribution of $\mathrm{Al}$ sites in the zeolite, the $\mathrm{Zn}$ loading, and the preparation method. ${ }^{81-83}$

Considering the ensemble of those XAS studies, it appears that the essence of the structural analysis of the $\mathrm{Zn}$ local structure relies on EXAFS spectroscopy. In particular, the evidence of an isolated $\mathrm{Zn}^{2+}$ ion stabilized on the zeolite framework is usually based on the absence of a strong $\mathrm{Zn}-\mathrm{Zn}$ contribution in the $2-4 \AA$ region. The fact that a $\mathrm{ZnO}$ cluster with substantial disorder would also generate the same type of EXAFS spectrum is sometimes either overlooked or discarded. $^{84,85}$ In other words, the absence of a $\mathrm{Zn}-\mathrm{Zn}$ peak is a necessary but not a sufficient condition to evidence isolated $\mathrm{Zn}^{2+}$ sites. In addition, the $\mathrm{Zn}^{2+}$ mononuclear sites are supposedly well-defined species, so that one may expect at least one $\mathrm{Zn}-\mathrm{Al}$ contribution to be taken into account in the EXAFS fitting procedure. As far as we know, this has only been done by the Torino research team using a DFT-assisted EXAFS fitting procedure. ${ }^{73}$ Another puzzling experimental fact revolves around the XANES spectroscopy data. For all published studies, the XANES fingerprint corresponding to the dehydrated state is quasi-identical with the same postedge features observed as in Figure 3, irrespective of the $\mathrm{Zn}$ loading, the $\mathrm{Zn} / \mathrm{Al}$ ratio, the zeolite framework and the preparation methods. The only variations are related to slight differences in the relative intensities of the two peaks positioned at 9664.7 and $9668.7 \mathrm{eV}$. Here there is a contradiction to solve, since it does not seem reasonable that all $\mathrm{Zn}$ structures ranging from mononuclear $\mathrm{Zn}$ species up to small $\mathrm{ZnO}$ clusters would provide the same XANES spectrum.

We approached this problem by using a method that combines DFT calculations with the recent implementation of evolutionary algorithms coupled with reverse Monte Carlo code for the fitting of EXAFS data, together with $a b$ initio calculations of the theoretical XANES spectra. The geometry optimization performed at the DFT level (periodic calculation with the CASTEP code ${ }^{86}$ ) was applied to an exhaustive list of structural models representing $\mathrm{Zn}$ sites in our $\mathrm{Zn}$-beta catalyst (IWI, $\mathrm{Zn} / \mathrm{Al}=1.07, \mathrm{Si} / \mathrm{Al}=22, \mathrm{Zn}$ loading $4.43 \mathrm{wt} \%$ ). A total of 39 candidate structures with their corresponding labels are described in detail in the Supporting Information. In summary, we have considered monomeric $\mathrm{Zn}^{2+}$ cations exchanged on four-, five-, and six-membered rings of the BEA framework having either one or two $\mathrm{Al}$ substitutions. Several combinations of $\mathrm{T}$ sites holding the aluminum substitution were investigated following Loewenstein's rule. ${ }^{87}$ With only one aluminum substitution, the charge compensation was implemented by adding a hydroxyl ligand bound to the $\mathrm{Zn}^{2+}$ cations. Dimeric and trimeric $\mathrm{Zn}$ oxide species were also relaxed together with a set of $\mathrm{Zn}$ oxide clusters carved into the hexagonal $\mathrm{ZnO}$ structure and placed within the 12-ring pore channel of the BEA framework. For the sake of completeness, we also included $\mathrm{Zn}^{2+}$ species anchored via hydroxyl groups from crystalline defects (e.g. silicon vacancies located on T sites). All optimized geometries are provided as CIF files in the Supporting Information.

In a subsequent step, the RMC/EA simulations were applied to the analysis of the $\mathrm{Zn} \mathrm{K}$ edge EXAFS spectra of the $\mathrm{Zn}$-beta 
a)

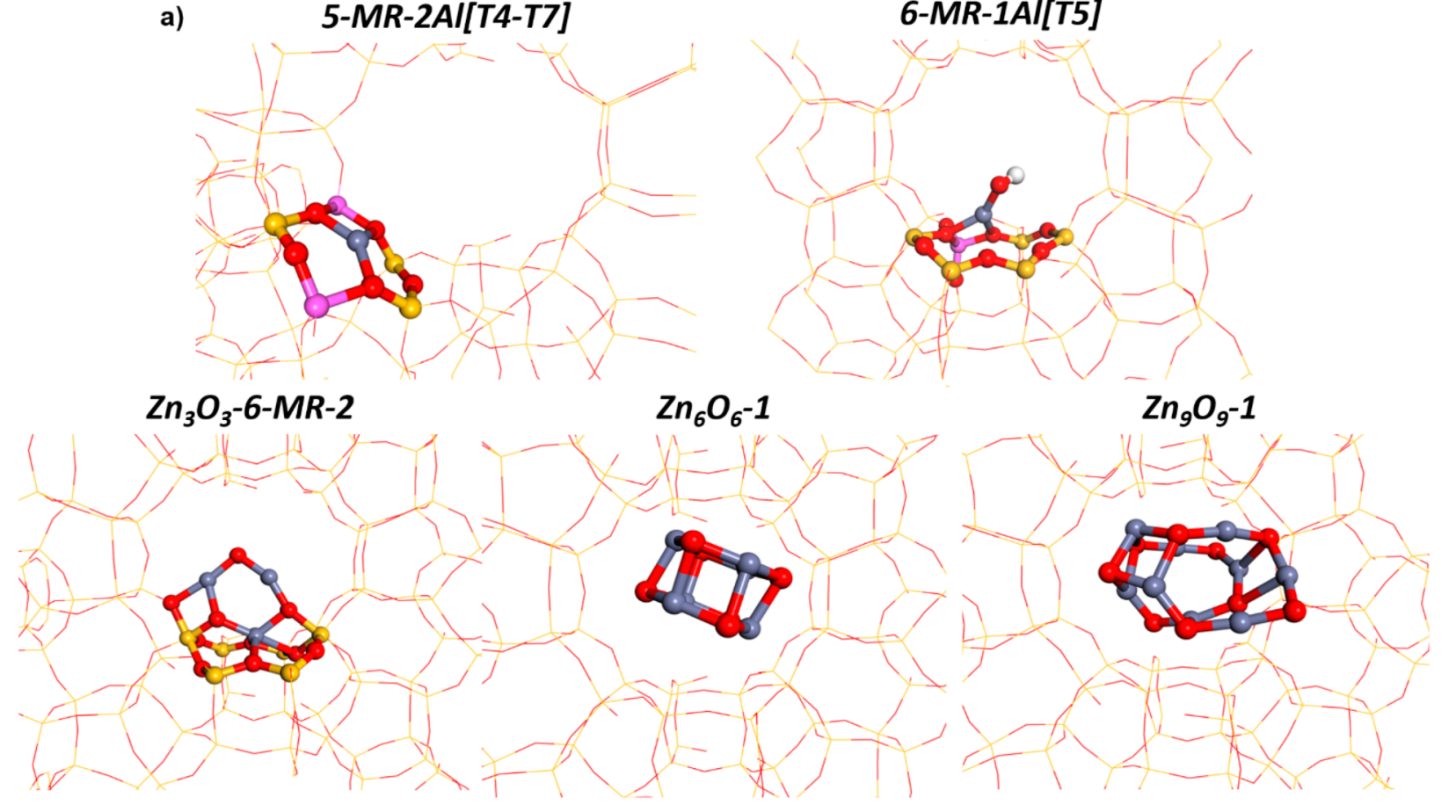

6-MR-1AI[T5]
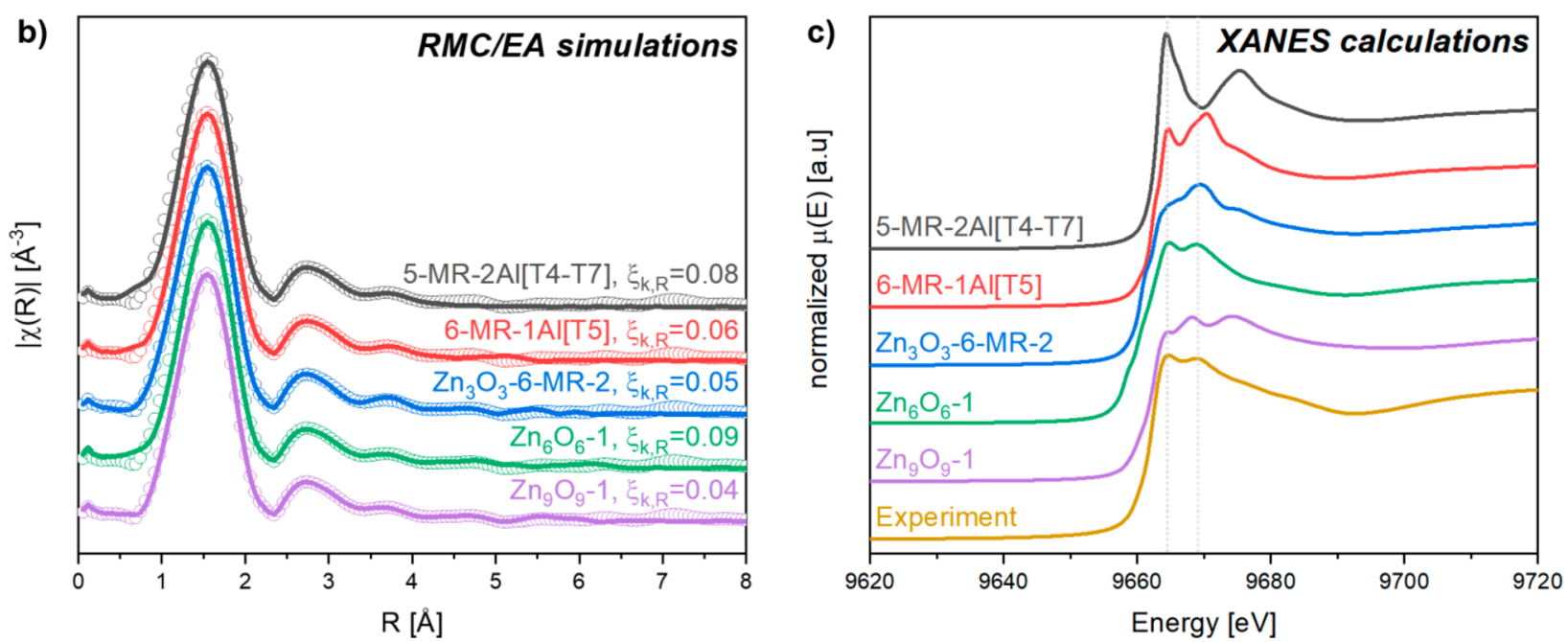

Figure 4. (a) DFT-optimized geometries for potential local environments of the $\mathrm{Zn}$ active sites for the best structural models selected by RMC/EA simulations. The atom color code as follows: $\mathrm{Zn}$, blue; $\mathrm{H}$, white; O, red; Al, pink; Si, yellow. (b) Experimental (open circles) and calculated by RMC/EA (solid line) Zn K-edge FT-EXAFS spectra for the Zn-beta (dual bed) catalyst after dehydration under $\mathrm{He}\left(T=300{ }^{\circ} \mathrm{C}, P=50\right.$ bar). (c) Theoretical XANES spectra calculated for the best structural models selected by RMC/EA simulations. The main postedge peaks positioned at 9664.7 and $9668.7 \mathrm{eV}$ of the experimental spectrum are marked by two vertical dotted lines. Calculated spectra were energy-shifted so that the first transition is aligned with the peak at $9664.7 \mathrm{eV}$.

catalyst dehydrated at $300{ }^{\circ} \mathrm{C}{ }^{48}$ The RMC simulation boxes were supercells dimensioned to include between 100 and 200 $\mathrm{Zn}$ atoms depending on the initial structural models. The maximum allowed atomic displacement was tuned down to 0.2 $\AA$ in order to closely preserve the original structure while leaving some flexibility to model the static and dynamic disorder. Single and multiple scattering paths were included up to half-path lengths of $6.5 \AA$. A comparison between the experimental and calculated EXAFS spectra was performed using the Morlet wavelet transform in the $k$-space range from 3.5 to $12.2 \AA$ and in the $R$-space range from 0.7 to $6 \AA$. The fit for all structural models is shown in Figure S24, and a selection of best fits is shown in Figure 4a,b. The first important observation is that all structures where the $\mathrm{Zn}^{2+}$ cations are isolated on four- and six-membered rings of the BEA framework are clearly rejected by the RMC/EA simulations. The case of the five-membered-ring structures is not as clear, since the fitting results all seem acceptable. A closer look at the overall results indicates that the best fit corresponds to structural models having a coordination number of about 3 oxygen atoms in the first shell. Accordingly, the integration of the radial distribution function (RDF) between 1 and $2.2 \AA$ provide a coordination number of between 2.8 and 3 oxygen atoms for the best structural models (Figure S25), and rough Gaussian fits of the first $\mathrm{Zn}-\mathrm{O}$ pair yield mean square relative displacement parameters between 0.007 and $0.009 \AA^{2}$ (all in 
good agreement with the previous first-shell analysis; Table S2). Next, small peaks in the FT-EXAFS spectra are due to a superposition of contributions from more distant atoms and multiple scattering effects. Examination of the corresponding RDF shows huge differences between the best structural models if we consider only the $2-4 \AA$ range. The RDFs above $2 \AA$ are nothing alike, which is absolutely expected, since among the five structural models selected by RMC/EA simulations (Figure S25) two of them are $\mathrm{Zn}^{2+}$ cations that are tricoordinated to framework oxygen atoms and three of them are $\mathrm{Zn}_{m} \mathrm{O}_{m}(m=3,6,9)$ clusters located in the 12-ring pore channel of the beta zeolite. In conclusion, these results serve as a compelling reminder that the same EXAFS data can be interpreted with both isolated $\mathrm{Zn}^{2+}$ cations and disordered $\mathrm{ZnO}$ clusters. It proves that the information present in the EXAFS spectra of Zn-modified zeolites is relatively limited and thus prevents the unequivocal establishment of this distinction, except when a clear and strong $\mathrm{Zn}-\mathrm{Zn}$ scattering path occurs when large $\mathrm{ZnO}$ crystallites are distributed in the sample.

On the other hand, XANES spectroscopy is much more sensitive to the three-dimensional geometry around the absorption site than EXAFS spectroscopy. First, the chemical nature of atoms bound to the absorber affects the XANES spectrum in some specific cases. Additionally, since the values of the electron inelastic mean free path at energies close to the absorption energy threshold are relatively important (>7 $\AA$ ), multiple scattering contributions can no longer be neglected, so that both the bond lengths and the bond angles influence the final spectral shape. Finally, the intensity of the transitions in the XANES spectrum is less attenuated by local disorder, meaning that the atoms in the long-range coordination shells retain a significant contribution. The latter is a clear advantage over EXAFS spectroscopy in the study of highly disordered systems. $^{46}$ So far, a qualitative interpretation of the pronounced splitting of the white line after dehydration was attributed to a coordination of $\mathrm{Zn}$ either in a tetrahedral or in a square-pyramidal symmetry. This explanation was based on a comparison with the general shape of XANES spectra published for a variety of $\mathrm{Zn}$ complexes. ${ }^{88-90}$ In the following, we strived to produce a quantitative analysis of the XANES data starting from the same structural models used as input for the RMC/EA simulations. Those calculations were conducted with the FDMNES code, which features monoelectronic calculations carried out in real space using clusters built around each nonequivalent absorbing atom (details provided in the Supporting Information). ${ }^{51}$ The accuracy of our calculation parameters was first benchmarked with reference $\mathrm{Zn}$ compounds whose crystalline structures are well-known $\left(\mathrm{Zn}, \mathrm{ZnO}, \mathrm{ZnS}, \mathrm{ZnCO}_{3}, \mathrm{Zn}\left(\mathrm{NO}_{3}\right)_{2} \cdot 6 \mathrm{H}_{2} \mathrm{O}, \mathrm{ZnSO}_{4} \cdot 7 \mathrm{H}_{2} \mathrm{O}\right)$ : an excellent agreement between theory and experiment is visualized in Figure S26. There are slight observable energy shifts and variations in intensity for some transitions, but most of the spectral features are well reproduced. This validates our ability to simulate the spectrum of an unknown compound if the input structure is a good approximation of the reality. All results are represented on Figure S27. As expected, the computed XANES spectra show a remarkable sensitivity toward the local environment of $\mathrm{Zn}$, since very distinct spectral characteristics are observed between each different group of $\mathrm{Zn}$ structural models. Within one structural family, the general spectral shape can look similar: for instance, within all $\mathrm{Zn}-\mathrm{OH}$ structural models or when $\mathrm{Zn}$ is occupying any $\mathrm{T}$ site position in the BEA framework. Nevertheless, we observe also large differences among spectra within the same group when the position of $\mathrm{Al}$ substitutions in the four-, five-, and sixmembered rings induced noticeable variation in distances and angles. In Figure 4c, we have regrouped the calculation corresponding to the structural models preselected by RMC/ EA simulations. The best agreement is easily identified for a $\mathrm{Zn}_{6} \mathrm{O}_{6}$ cluster located in the 12-ring pore channel $\left(\mathrm{Zn}_{6} \mathrm{O}_{6}-1\right)$. The latter spectrum matches perfectly the two postedge peaks of the experimental spectrum and the overall spectral shape. In contrast, the model with a $\mathrm{Zn}^{2+}$ cation immobilized on fivemembered rings (5-MR-2Al[T4-T7]) and the model with a disordered $\mathrm{Zn}_{9} \mathrm{O}_{9}$ cluster $\left(\mathrm{Zn}_{9} \mathrm{O}_{9}-1\right)$ are clearly excluded. The models with a $\mathrm{Zn}-\mathrm{OH}$ moiety (6-MR-1Al[T5]) or a $\mathrm{Zn}_{3} \mathrm{O}_{3}\left(\mathrm{Zn}_{3} \mathrm{O}_{3}-6-\mathrm{MR}-2\right)$ cluster located on a 6-MR ring lie in a gray area, because the postedge peaks appear at the correct energies but their relative intensities are inverted. Those two structural models cannot be excluded absolutely if we consider that the experimental spectrum could represent a mixture of Zn species. This could also explain some variation in intensity for the postedge peaks observed in the literature. Eventually, the theoretical results are strongly in favor of the formation of $\mathrm{Zn}_{6} \mathrm{O}_{6}$ cluster in the 12-ring pore channel upon dehydration of the $\mathrm{Zn}$-beta catalyst, whose structure remains unaffected during the $\mathrm{CO}_{2}$ hydrogenation reaction.

In summary, the $\mathrm{Zn}$ present in zeolite beta likely provides a hydrogen activation function that possibly inhibits the formation of deactivating polyaromatics, since the olefins formed due to MTH are presumably being hydrogenated on the $\mathrm{Zn}$ sites before they can cyclize/aromatize (Figure 5).

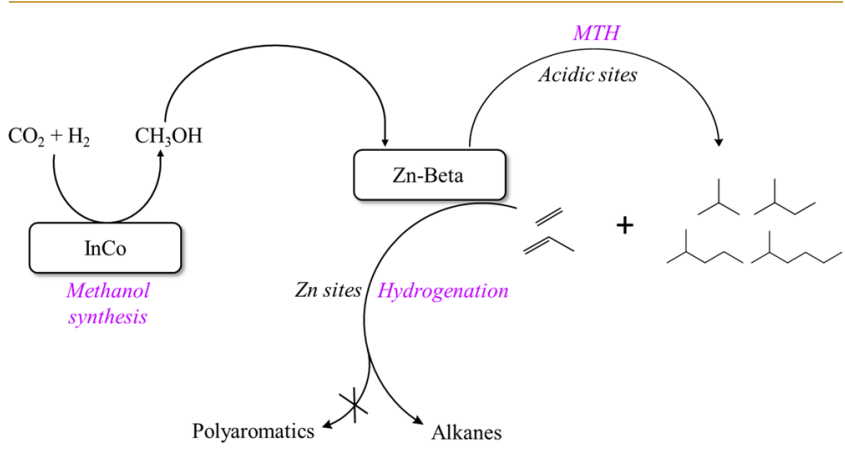

Figure 5. Schematic representation of the possible mechanistic role of $\mathrm{Zn}$-beta in the catalytic performance of InCo $+\mathrm{Zn}$-beta in the dualbed configuration.

Since these hydrogenating $\mathrm{Zn}$ sites are in much closer proximity to the acid sites of the zeolite in comparison to the hydrogenating sites provided by the InCo catalyst in the InCo + beta (mixed bed) configuration, it could be the likely reason for the significant enhancement of the more valuable $\mathrm{C}_{5}-\mathrm{C}_{7}$ isoparaffin fraction in hydrocarbons (vide supra) for the InCo + Zn-beta (dual bed) in comparison to the InCo + beta (mixed bed). ${ }^{33}$ The detailed structural characterization of $\mathrm{Zn}$ inside zeolite beta provided here serves as a strong foundation for further mechanistic investigation that is currently ongoing.

\section{CONCLUSION}

In conclusion, our results demonstrate that catalytic engineering can play a significant role in the thermocatalytic conversion of $\mathrm{CO}_{2}$ with multifunctional catalysts. We have observed that the product distribution is markedly different depending on the catalyst configuration and zeolite modification. The bed 
configuration (mixed or dual) plays a pivotal role in the catalytic performance, as the hydrogenation function of the impregnated $\mathrm{Zn}$ helps to prolong the zeolite lifetime. Moreover, with $\mathrm{Zn}$ modification, we were able to achieve a selectivity of isoparaffins of up to $\sim 85 \%$ among hydrocarbons, which is among the highest values reported so far. An operando XAS analysis of the catalyst combination reveals that Co does not undergo any changes regardless of the catalyst configuration (InCo + beta mixed bed or InCo $+\mathrm{Zn}$-beta dual bed). Furthermore, a combined XANES and EXAFS analysis revealed that the structure of $\mathrm{Zn}$ inside zeolite beta is likely in the form of clusters of $\mathrm{Zn}_{6} \mathrm{O}_{6}$. This is in contrast to previously reported results where the morphology of $\mathrm{Zn}$ inside the zeolite having characteristics similar to those of our sample (in terms of $\mathrm{Zn}$ loading, $\mathrm{Si} / \mathrm{Al}$ ratio, and/or $\mathrm{Zn} / \mathrm{Al}$ ratio) was reported to be monomeric $\mathrm{Zn}^{2+}$ cations typically on the basis of an EXAFS analysis alone. We hope that these results can help to overcome the multiple challenges associated with thermocatalytic conversion of $\mathrm{CO}_{2}$ and support the transition to a circular carbon economy.

\section{ASSOCIATED CONTENT}

\section{Supporting Information}

The following files are available free of charge: Figures S1-S27 and Tables S1-S2 (PDF) (CIF) The Supporting Information is available free of charge at https://pubs.acs.org/doi/10.1021/ jacsau.1c00317.

Characterization of catalysts, comparison with the state of the art, additional XAS details, and additional figures and tables (PDF)

Structural models of all $\mathrm{Zn}$ species discussed in this work (ZIP)

\section{AUTHOR INFORMATION}

Corresponding Author

Jorge Gascon - King Abdullah University of Science and Technology, KAUST Catalysis Center (KCC), Thuwal 23955, Saudi Arabia; 이잉.org/0000-0001-7558-7123; Email: jorge.gascon@kaust.edu.sa

\section{Authors}

Abhay Dokania - King Abdullah University of Science and Technology, KAUST Catalysis Center (KCC), Thuwal 23955, Saudi Arabia

Samy Ould-Chikh - King Abdullah University of Science and Technology, KAUST Catalysis Center (KCC), Thuwal 23955, Saudi Arabia; 이잉.org/0000-0002-3486-0944

Adrian Ramirez - King Abdullah University of Science and Technology, KAUST Catalysis Center (KCC), Thuwal 23955, Saudi Arabia; (ㅇ) orcid.org/0000-0001-5036-1355

Jose Luis Cerrillo - King Abdullah University of Science and Technology, KAUST Catalysis Center (KCC), Thuwal 23955, Saudi Arabia; 이이이.org/0000-0001-8824-8294

Antonio Aguilar - Institut Neel, UPR 2940 CNRS-Université Grenoble Alpes, F-38000 Grenoble, France

Artem Russkikh - King Abdullah University of Science and Technology, KAUST Catalysis Center (KCC), Thuwal 23955, Saudi Arabia

Ahmed Alkhalaf - King Abdullah University of Science and Technology, KAUST Catalysis Center (KCC), Thuwal 23955, Saudi Arabia
Idoia Hita - King Abdullah University of Science and Technology, KAUST Catalysis Center (KCC), Thuwal 23955, Saudi Arabia

Anastasiya Bavykina - King Abdullah University of Science and Technology, KAUST Catalysis Center (KCC), Thuwal 23955, Saudi Arabia

Genrikh Shterk - King Abdullah University of Science and Technology, KAUST Catalysis Center (KCC), Thuwal 23955, Saudi Arabia

Nimer Wehbe - King Abdullah University of Science and Technology, Imaging and Characterization Core Laboratories, Thuwal 23955, Saudi Arabia

Alain Prat - Institut Neel, UPR 2940 CNRS-Université Grenoble Alpes, F-38000 Grenoble, France

Eric Lahera - OSUG, UMS 832 CNRS-Université Grenoble Alpes, F-38041 Grenoble, France

Pedro Castaño - King Abdullah University of Science and Technology, KAUST Catalysis Center (KCC), Thuwal 23955, Saudi Arabia; (1) orcid.org/0000-0002-6454-9321

Emiliano Fonda - Synchrotron SOLEIL, L'orme des Merisiers, 91192 Gif-sur-Yvette, France; 이이.org/00000001-6584-4587

Jean-Louis Hazemann - Institut Neel, UPR 2940 CNRSUniversité Grenoble Alpes, F-38000 Grenoble, France

Complete contact information is available at:

https://pubs.acs.org/10.1021/jacsau.1c00317

\section{Author Contributions}

The manuscript was written through contributions of all authors. All authors have given approval to the final version of the manuscript.

\section{Funding}

Funding for this work was provided by King Abdullah University of Science \& Technology (KAUST).

Notes

The authors declare no competing financial interest.

\section{ACKNOWLEDGMENTS}

We thank Dr. Jullian Vittenet for carrying out ICP measurements of the samples. We also thank Sandra Ramirez Cherbuy for creating the graphical abstract of this manuscript. Janis Timoshenko is warmly thanked for his initial guidance in preparing the EvAX code input files to perform the EA-RMC calculations. The authors gratefully acknowledge the SOLEIL Synchrotron (Gif-sur-Yvette, France) for the provision of beamtime (proposal: 20190854) for XAS experiments carried out on the SAMBA beamline and the support of their staff.

\section{REFERENCES}

(1) Lee, R. P.; Keller, F.; Meyer, B. A concept to support the transformation from a linear to circular carbon economy: net zero emissions, resource efficiency and conservation through a coupling of the energy, chemical and waste management sectors. Clean Energy 2017, 1 (1), 102-113.

(2) Sanz-Pérez, E. S.; Murdock, C. R.; Didas, S. A.; Jones, C. W. Direct Capture of CO2 from Ambient Air. Chem. Rev. 2016, 116 (19), 11840-11876.

(3) IEA Putting $\mathrm{CO}_{2}$ to Use; IEA: Paris, 2019

(4) De, S.; Dokania, A.; Ramirez, A.; Gascon, J. Advances in the Design of Heterogeneous Catalysts and Thermocatalytic Processes for CO2 Utilization. ACS Catal. 2020, 10 (23), 14147-14185. 
(5) Tista, M.; Gager, M.; Gaisbauer, S.; Ullrich, B. European Union Emission Inventory Report 1990-2017 under the UNECE Convention on Long-Range Transboundary Air Pollution (LRTAP); Publications Office of the European Union: 2019.

(6) Dittmeyer, R.; Klumpp, M.; Kant, P.; Ozin, G. Crowd oil not crude oil. Nat. Commun. 2019, 10 (1), 1818.

(7) Dokania, A.; Ramirez, A.; Bavykina, A.; Gascon, J. Heterogeneous Catalysis for the Valorization of $\mathrm{CO}_{2}$ : Role of Bifunctional Processes in the Production of Chemicals. ACS Energy Lett. 2019, 4 (1), 167-176.

(8) Inui, T. Effective conversion of $\mathrm{CO} 2$ to valuable compounds by using multifunctional catalysts. In $\mathrm{CO} 2$ Conversion and Utilization; Song, C., Gaffney, A. F., Fujimoto, K., Eds.; ACS Publications: 2002; Vol. 809, pp 130-152.

(9) Yang, H.; Zhang, C.; Gao, P.; Wang, H.; Li, X.; Zhong, L.; Wei, W.; Sun, Y. A Review of the Catalytic Hydrogenation of Carbon Dioxide into Value-Added Hydrocarbons. Catal. Sci. Technol. 2017, 7 (20), 4580-4598.

(10) Li, J.; Wang, L.; Cao, Y.; Zhang, C.; He, P.; Li, H. Recent advances on the reduction of $\mathrm{CO} 2$ to important $\mathrm{C} 2+$ oxygenated chemicals and fuels. Chin. J. Chem. Eng. 2018, 26 (11), 2266-2279.

(11) Zhou, W.; Cheng, K.; Kang, J.; Zhou, C.; Subramanian, V.; Zhang, Q.; Wang, Y. New horizon in C1 chemistry: breaking the selectivity limitation in transformation of syngas and hydrogenation of CO2 into hydrocarbon chemicals and fuels. Chem. Soc. Rev. 2019, 48 (12), 3193-3228.

(12) Panzone, C.; Philippe, R.; Chappaz, A.; Fongarland, P.; Bengaouer, A. Power-to-Liquid catalytic $\mathrm{CO} 2$ valorization into fuels and chemicals: focus on the Fischer-Tropsch route. J. CO2 Util. 2020, 38, 314-347.

(13) Li, Z.; Wang, J.; Qu, Y.; Liu, H.; Tang, C.; Miao, S.; Feng, Z.; An, H.; Li, C. Highly Selective Conversion of Carbon Dioxide to Lower Olefins. ACS Catal. 2017, 7 (12), 8544-8548.

(14) Gao, P.; Dang, S.; Li, S.; Bu, X.; Liu, Z.; Qiu, M.; Yang, C.; Wang, H.; Zhong, L.; Han, Y.; Liu, Q.; Wei, W.; Sun, Y. Direct Production of Lower Olefins from $\mathrm{CO}_{2}$ Conversion via Bifunctional Catalysis. ACS Catal. 2018, 8 (1), 571-578.

(15) Ramirez, A.; Dutta Chowdhury, A.; Caglayan, M.; RodriguezGomez, A.; Wehbe, N.; Abou-Hamad, E.; Gevers, L.; Ould-Chikh, S.; Gascon, J. Coated sulfated zirconia/SAPO-34 for the direct conversion of $\mathrm{CO} 2$ to light olefins. Catal. Sci. Technol. 2020, 10 (5), $1507-1517$.

(16) Dang, S.; Li, S.; Yang, C.; Chen, X.; Li, X.; Zhong, L.; Gao, P.; Sun, Y. Selective Transformation of $\mathrm{CO} 2$ and $\mathrm{H} 2$ into Lower Olefins over In2O3-ZnZrOx/SAPO-34 Bifunctional Catalysts. ChemSusChem 2019, 12 (15), 3582-3591.

(17) Ni, Y.; Chen, Z.; Fu, Y.; Liu, Y.; Zhu, W.; Liu, Z. Selective Conversion of $\mathrm{CO}_{2}$ and $\mathrm{H}_{2}$ into Aromatics. Nat. Commun. 2018, 9 (1), 3457

(18) Wang, Y.; Gao, W.; Kazumi, S.; Li, H.; Yang, G.; Tsubaki, N. Direct and Oriented Conversion of $\mathrm{CO} 2$ into Value-Added Aromatics. Chem. - Eur. J. 2019, 25 (20), 5149-5153.

(19) Wang, S.; Wu, T.; Lin, J.; Tian, J.; Ji, Y.; Pei, Y.; Yan, S.; Qiao, M.; Xu, H.; Zong, B. FeK on 3D Graphene-Zeolite Tandem Catalyst with High Efficiency and Versatility in Direct CO2 Conversion to Aromatics. ACS Sustainable Chem. Eng. 2019, 7 (21), 17825-17833.

(20) Wang, Y.; Kazumi, S.; Gao, W.; Gao, X.; Li, H.; Guo, X.; Yoneyama, Y.; Yang, G.; Tsubaki, N. Direct conversion of CO2 to aromatics with high yield via a modified Fischer-Tropsch synthesis pathway. Appl. Catal., B 2020, 269, 118792.

(21) Xu, Y.; Wang, T.; Shi, C.; Liu, B.; Jiang, F.; Liu, X. Experimental Investigation on the Two-Sided Effect of Acidic HZSM-5 on the Catalytic Performance of Composite Fe-Based Fischer-Tropsch Catalysts and HZSM-5 Zeolite in the Production of Aromatics from CO2/H2. Ind. Eng. Chem. Res. 2020, 59 (18), 8581-8591.

(22) Wei, J.; Ge, Q.; Yao, R.; Wen, Z.; Fang, C.; Guo, L.; Xu, H.; Sun, J. Directly Converting $\mathrm{CO}_{2}$ into a Gasoline Fuel. Nat. Commun. 2017, 8, 15174
(23) Gao, P.; Li, S.; Bu, X.; Dang, S.; Liu, Z.; Wang, H.; Zhong, L.; Qiu, M.; Yang, C.; Cai, J.; Wei, W.; Sun, Y. Direct Conversion of $\mathrm{CO}_{2}$ into Liquid Fuels with High Selectivity over a Bifunctional Catalyst. Nat. Chem. 2017, 9, 1019.

(24) Liu, Z.; Ni, Y.; Sun, T.; Zhu, W.; Liu, Z. Conversion of CO2 and $\mathrm{H} 2$ into propane over InZrOx and SSZ-13 composite catalyst. J. Energy Chem. 2021, 54, 111-117.

(25) Tong, M.; Hondo, E.; Gapu Chizema, L.; Du, C.; Ma, Q.; Mo, S.; Lu, C.; Lu, P.; Tsubaki, N. Hydrogenation of CO2 to LPG over CuZnZr/MeSAPO-34 catalysts. New J. Chem. 2020, 44 (22), 93289336.

(26) Wei, J.; Yao, R.; Ge, Q.; Wen, Z.; Ji, X.; Fang, C.; Zhang, J.; Xu, $\mathrm{H}$.; Sun, J. Catalytic Hydrogenation of $\mathrm{CO}_{2}$ to Isoparaffins over FeBased Multifunctional Catalysts. ACS Catal. 2018, 8 (11), 99589967.

(27) Tan, Y.; Fujiwara, M.; Ando, H.; Xu, Q.; Souma, Y.; Inui, T.; Anpo, M.; Izui, K.; Yanagida, S.; Yamaguchi, T. Selective Formation of iso-Butane from Carbon Dioxide and Hydrogen over Composite Catalysts. Stud. Surf. Sci. Catal. 1998, 114, 435-438.

(28) Noreen, A.; Li, M.; Fu, Y.; Amoo, C. C.; Wang, J.; Maturura, E.; Du, C.; Yang, R.; Xing, C.; Sun, J. One-Pass Hydrogenation of $\mathrm{CO} 2$ to Multibranched Isoparaffins over Bifunctional Zeolite-Based Catalysts. ACS Catal. 2020, 10 (23), 14186-14194.

(29) Wang, X.; Zeng, C.; Gong, N.; Zhang, T.; Wu, Y.; Zhang, J.; Song, F.; Yang, G.; Tan, Y. Effective Suppression of CO Selectivity for CO2 Hydrogenation to High-Quality Gasoline. ACS Catal. 2021, 11 (3), 1528-1547.

(30) Ramirez, A.; Sarathy, S. M.; Gascon, J. CO2 Derived E-Fuels: Research Trends, Misconceptions, and Future Directions. Trends in Chemistry 2020, 2 (9), 785-795.

(31) Wang, X.; Yang, G.; Zhang, J.; Chen, S.; Wu, Y.; Zhang, Q.; Wang, J.; Han, Y.; Tan, Y. Synthesis of Isoalkanes over a Core ( $\mathrm{Fe}-$ $\mathrm{Zn}-\mathrm{Zr}$ )-Shell (Zeolite) Catalyst by $\mathrm{CO}_{2}$ Hydrogenation. Chem. Commun. 2016, 52 (46), 7352-7355.

(32) Demirbas, A.; Balubaid, M. A.; Basahel, A. M.; Ahmad, W.; Sheikh, M. H. Octane Rating of Gasoline and Octane Booster Additives. Pet. Sci. Technol. 2015, 33 (11), 1190-1197.

(33) Schaidle, J. A.; Ruddy, D. A.; Habas, S. E.; Pan, M.; Zhang, G.; Miller, J. T.; Hensley, J. E. Conversion of Dimethyl Ether to 2,2,3Trimethylbutane over a Cu/BEA Catalyst: Role of $\mathrm{Cu}$ Sites in Hydrogen Incorporation. ACS Catal. 2015, 5 (3), 1794-1803.

(34) Ruddy, D. A.; Hensley, J. E.; Nash, C. P.; Tan, E. C. D.; Christensen, E.; Farberow, C. A.; Baddour, F. G.; Van Allsburg, K. M.; Schaidle, J. A. Methanol to high-octane gasoline within a marketresponsive biorefinery concept enabled by catalysis. Nat. Catal. 2019, 2 (7), 632-640.

(35) Bavykina, A.; Yarulina, I.; Al Abdulghani, A. J.; Gevers, L.; Hedhili, M. N.; Miao, X.; Galilea, A. R.; Pustovarenko, A.; Dikhtiarenko, A.; Cadiau, A.; Aguilar-Tapia, A.; Hazemann, J.-L.; Kozlov, S. M.; Oud-Chikh, S.; Cavallo, L.; Gascon, J. Turning a Methanation Co Catalyst into an In-Co Methanol Producer. ACS Catal. 2019, 9, 6910-6918.

(36) Tsoukalou, A.; Abdala, P. M.; Stoian, D.; Huang, X.; Willinger, M.-G.; Fedorov, A.; Müller, C. R. Structural Evolution and Dynamics of an In2O3 Catalyst for CO2 Hydrogenation to Methanol: An Operando XAS-XRD and In Situ TEM Study. J. Am. Chem. Soc. 2019, 141 (34), 13497-13505.

(37) Bansode, A.; Guilera, G.; Cuartero, V.; Simonelli, L.; Avila, M.; Urakawa, A. Performance and characteristics of a high pressure, high temperature capillary cell with facile construction for operando $x$-ray absorption spectroscopy. Rev. Sci. Instrum. 2014, 85 (8), 084105.

(38) Martin, T. D.; Brockhoff, C. A.; Creed, J. T.; Long, S. E. Method 200.7, Revision 4.4: Determination of Metals and Trace Elements in Water and Wastes by Inductively Coupled Plasma-Atomic Emission Spectrometry. US EPA: 1994.

(39) Rouquerol, J.; Llewellyn, P.; Rouquerol, F.; Llewellyn, P. L.; Rodriquez-Reinoso, F.; Rouqerol, J.; Seaton, N. Is the BET Equation Applicable to Microporous Adsorbents? Stud. Surf. Sci. Catal. 2007, 160, 49-56. 
(40) Emeis, C. A. Determination of Integrated Molar Extinction Coefficients for Infrared Absorption Bands of Pyridine Adsorbed on Solid Acid Catalysts. J. Catal. 1993, 141 (2), 347-354.

(41) Belin, S.; Briois, V.; Traverse, A.; Idir, M.; Moreno, T.; Ribbens, M. SAMBA a New Beamline at SOLEIL for XRay Absorption Spectroscopy in the $440 \mathrm{keV}$ Energy Range. Phys. Scr. 2005, 980.

(42) Aguilar-Tapia, A.; Ould-Chikh, S.; Lahera, E.; Prat, A.; Delnet, W.; Proux, O.; Kieffer, I.; Basset, J.-M.; Takanabe, K.; Hazemann, J.-L. A new high temperature reactor for operando XAS: Application for the dry reforming of methane over $\mathrm{Ni} / \mathrm{ZrO} 2$ catalyst. Rev. Sci. Instrum. 2018, 89 (3), 035109.

(43) Testemale, D.; Argoud, R.; Geaymond, O.; Hazemann, J.-L. High pressure/high temperature cell for $\mathrm{x}$-ray absorption and scattering techniques. Rev. Sci. Instrum. 2005, 76 (4), 043905.

(44) Landrot, G. FASTOSH: a software to process XAFS data for geochemical \& environmental applications. Goldschmidt Abstracts 2018, 1402 .

(45) Ravel, B.; Newville, M. ATHENA, ARTEMIS, HEPHAESTUS: data analysis for X-ray absorption spectroscopy using IFEFFIT. J. Synchrotron Radiat. 2005, 12 (4), 537-541.

(46) Rehr, J. J.; Albers, R. C. Theoretical approaches to x-ray absorption fine structure. Rev. Mod. Phys. 2000, 72 (3), 621-654.

(47) Aminoff, G. Ueber Lauephotogramme und Struktur von Zinkit. Z. Kristallogr. - Cryst. Mater. 1921, 56, 495-505.

(48) Timoshenko, J.; Kuzmin, A.; Purans, J. EXAFS study of hydrogen intercalation into $\mathrm{ReO}$ using the evolutionary algorithm. $J$. Phys.: Condens. Matter 2014, 26 (5), 055401.

(49) Ankudinov, A. L.; Ravel, B.; Rehr, J. J.; Conradson, S. D. Realspace multiple-scattering calculation and interpretation of $\mathrm{x}$-rayabsorption near-edge structure. Phys. Rev. B: Condens. Matter Mater. Phys. 1998, 58 (12), 7565-7576.

(50) Timoshenko, J.; Kuzmin, A. Wavelet data analysis of EXAFS spectra. Comput. Phys. Commun. 2009, 180 (6), 920-925.

(51) Bunău, O.; Joly, Y. Self-consistent aspects of x-ray absorption calculations. J. Phys.: Condens. Matter 2009, 21 (34), 345501.

(52) Guda, S. A.; Guda, A. A.; Soldatov, M. A.; Lomachenko, K. A.; Bugaev, A. L.; Lamberti, C.; Gawelda, W.; Bressler, C.; Smolentsev, G.; Soldatov, A. V.; Joly, Y. Optimized Finite Difference Method for the Full-Potential XANES Simulations: Application to Molecular Adsorption Geometries in MOFs and Metal-Ligand Intersystem Crossing Transients. J. Chem. Theory Comput. 2015, 11 (9), 45124521.

(53) Krause, M. O.; Oliver, J. H. Natural widths of atomic K and L levels, K $\alpha$ X-ray lines and several KLL Auger lines. J. Phys. Chem. Ref. Data 1979, 8 (2), 329-338.

(54) Yarulina, I.; Chowdhury, A. D.; Meirer, F.; Weckhuysen, B. M.; Gascon, J. Recent Trends and Fundamental insights in the Methanolto-Hydrocarbons Process. Nat. Catal. 2018, 1 (6), 398-411.

(55) Olsbye, U.; Svelle, S.; Bjørgen, M.; Beato, P.; Janssens, T. V. W.; Joensen, F.; Bordiga, S.; Lillerud, K. P. Conversion of Methanol to Hydrocarbons: How Zeolite Cavity and Pore Size Controls Product Selectivity. Angew. Chem., Int. Ed. 2012, 51 (24), 5810-5831.

(56) Mikkelsen, Ø.; Kolboe, S. The conversion of methanol to hydrocarbons over zeolite H-beta. Microporous Mesoporous Mater. 1999, 29 (1), 173-184.

(57) Scharnagl, F. K.; Hertrich, M. F.; Ferretti, F.; Kreyenschulte, C.; Lund, H.; Jackstell, R.; Beller, M. Hydrogenation of terminal and internal olefins using a biowaste-derived heterogeneous cobalt catalyst. Science Advances 2018, 4 (9), eaau1248.

(58) Arora, S. S.; Shi, Z.; Bhan, A. Mechanistic Basis for Effects of High-Pressure H2 Cofeeds on Methanol-to-Hydrocarbons Catalysis over Zeolites. ACS Catal. 2019, 9 (7), 6407-6414.

(59) Deldari, H. Suitable catalysts for hydroisomerization of longchain normal paraffins. Appl. Catal., A 2005, 293, 1-10.

(60) Ahn, J. H.; Temel, B.; Iglesia, E. Selective Homologation Routes to 2,2,3-Trimethylbutane on Solid Acids. Angew. Chem., Int. Ed. 2009, 48 (21), 3814-3816.

(61) Ramirez, A.; Dutta Chowdhury, A.; Dokania, A.; Cnudde, P.; Caglayan, M.; Yarulina, I.; Abou-Hamad, E.; Gevers, L.; Ould-Chikh,
S.; De Wispelaere, K.; van Speybroeck, V.; Gascon, J. Effect of Zeolite Topology and Reactor Configuration on the Direct Conversion of $\mathrm{CO}_{2}$ to Light Olefins and Aromatics. ACS Catal. 2019, 9 (7), 63206334.

(62) Dokania, A.; Dutta Chowdhury, A.; Ramirez, A.; Telalovic, S.; Abou-Hamad, E.; Gevers, L.; Ruiz-Martinez, J.; Gascon, J. Acidity modification of ZSM-5 for enhanced production of light olefins from CO2. J. Catal. 2020, 381, 347-354.

(63) Feller, A.; Lercher, J. A. Chemistry and Technology of Isobutane/Alkene Alkylation Catalyzed by Liquid and Solid Acids. Adv. Catal. 2004, 48, 229-295.

(64) Feller, A.; Zuazo, I.; Guzman, A.; Barth, J. O.; Lercher, J. A. Common mechanistic aspects of liquid and solid acid catalyzed alkylation of isobutane with n-butene. J. Catal. 2003, 216 (1), 313323.

(65) Matieva, Z. M.; Kolesnichenko, N. V.; Snatenkova, Y. M.; Khadzhiev, S. N. Features of Zinc Modification of a Zeolite Catalyst for Dimethyl Ether Conversion to Synthetic Liquid Hydrocarbons. Pet. Chem. 2019, 59 (7), 745-750.

(66) Su, X.; Zhang, K.; Snatenkova, Y.; Matieva, Z.; Bai, X.; Kolesnichenko, N.; Wu, W. High-efficiency nano [Zn,Al]ZSM-5 bifunctional catalysts for dimethyl ether conversion to isoparaffin-rich gasoline. Fuel Process. Technol. 2020, 198, 106242.

(67) Snatenkova, Y. M.; Kolesnichenko, N. V.; Matieva, Z. M.; Maximov, A. L. Dimethyl Ether Conversion to Gasoline Hydrocarbons over Nanosized Zeolite Catalysts: Effect of Modifier Nature. Pet. Chem. 2019, 59 (12), 1331-1336.

(68) Snatenkova, Y. M.; Ionin, D. A.; Kolesnichenko, N. V.; Matieva, Z. M. Dimethyl Ether Conversion to Liquid Hydrocarbons: Effect of $\mathrm{SiO} 2 / \mathrm{Al} 2 \mathrm{O} 3 \mathrm{Molar}$ Ratio and Zinc Introduction Method on the Properties of a Nanosized Zeolite Catalyst. Pet. Chem. 2019, 59 (5), $535-539$.

(69) Wang, Y.; Wang, G.; van der Wal, L. I.; Cheng, K.; Zhang, Q.; de Jong, K. P.; Wang, Y. Visualizing Element Migration over Bifunctional Metal-Zeolite Catalysts and its Impact on Catalysis. Angew. Chem., Int. Ed. 2021, 60 (32), 17735-17743.

(70) Yilmaz, B.; Müller, U.; Feyen, M.; Maurer, S.; Zhang, H.; Meng, X.; Xiao, F.-S.; Bao, X.; Zhang, W.; Imai, H.; Yokoi, T.; Tatsumi, T.; Gies, H.; De Baerdemaeker, T.; De Vos, D. A new catalyst platform: zeolite Beta from template-free synthesis. Catal. Sci. Technol. 2013, 3 (10), 2580-2586.

(71) Pustovarenko, A.; Dikhtiarenko, A.; Bavykina, A.; Gevers, L.; Ramírez, A.; Russkikh, A.; Telalovic, S.; Aguilar, A.; Hazemann, J.-L.; Ould-Chikh, S.; Gascon, J. Metal-Organic Framework-Derived Synthesis of Cobalt Indium Catalysts for the Hydrogenation of CO2 to Methanol. ACS Catal. 2020, 10 (9), 5064-5076.

(72) D’Angelo, P.; Benfatto, M.; Della Longa, S.; Pavel, N. V. Combined XANES and EXAFS analysis of $\mathrm{Co}^{2+}, \mathrm{Ni}^{2+}$ and $\mathrm{Zn}^{2+}$ aqueous solutions. Phys. Rev. B: Condens. Matter Mater. Phys. 2002, 66 (6), 064209.

(73) Pinilla-Herrero, I.; Borfecchia, E.; Holzinger, J.; Mentzel, U. V.; Joensen, F.; Lomachenko, K. A.; Bordiga, S.; Lamberti, C.; Berlier, G.; Olsbye, U.; Svelle, S.; Skibsted, J.; Beato, P. High Zn/Al ratios enhance dehydrogenation vs hydrogen transfer reactions of Zn-ZSM5 catalytic systems in methanol conversion to aromatics. J. Catal. 2018, 362, 146-163.

(74) Biscardi, J. A.; Meitzner, G. D.; Iglesia, E. Structure and Density of Active $\mathrm{Zn}$ Species in $\mathrm{Zn} / \mathrm{H}-\mathrm{ZSM}$ S Propane Aromatization Catalysts. J. Catal. 1998, 179 (1), 192-202.

(75) Almutairi, S. M. T.; Mezari, B.; Magusin, P. C. M. M.; Pidko, E. A.; Hensen, E. J. M. Structure and Reactivity of Zn-Modified ZSM-5 Zeolites: The Importance of Clustered Cationic Zn Complexes. ACS Catal. 2012, 2 (1), 71-83.

(76) Gabrienko, A. A.; Arzumanov, S. S.; Toktarev, A. V.; Danilova, I. G.; Prosvirin, I. P.; Kriventsov, V. V.; Zaikovskii, V. I.; Freude, D.; Stepanov, A. G. Different Efficiency of $\mathrm{Zn2}+$ and $\mathrm{ZnO}$ Species for Methane Activation on Zn-Modified Zeolite. ACS Catal. 2017, 7 (3), $1818-1830$. 
(77) Oda, A.; Ohkubo, T.; Yumura, T.; Kobayashi, H.; Kuroda, Y. Synthesis of an unexpected $\left[\mathrm{Zn}_{2}\right]^{2+}$ species utilizing an MFI-type zeolite as a nano-reaction pot and its manipulation with light and heat. Dalton Trans. 2015, 44 (21), 10038-10047.

(78) Penzien, J.; Abraham, A.; van Bokhoven, J. A.; Jentys, A.; Müller, T. E.; Sievers, C.; Lercher, J. A. Generation and Characterization of Well-Defined Zn2+ Lewis Acid Sites in Ion Exchanged Zeolite BEA. J. Phys. Chem. B 2004, 108 (13), 4116-4126.

(79) Gao, J.; Wei, C.; Dong, M.; Wang, G.; Li, Z.; Qin, Z.; Wang, J.; Fan, W. Evolution of Zn Species on Zn/HZSM-5 Catalyst under H2 Pretreated and its Effect on Ethylene Aromatization. ChemCatChem 2019, 11 (16), 3892-3902.

(80) Hennig, C.; Thiel, F.; Hallmeiér, K. H.; Szargan, R.; Hagen, A.; Roessner, F. Characterization of Zn centers in ZSM-5 zeolites with Xray absorption spectroscopy. Spectrochimica Acta Part A: Molecular Spectroscopy 1993, 49 (10), 1495-1497.

(81) Dědeček, J.; Tabor, E.; Sklenak, S. Tuning the Aluminum Distribution in Zeolites to Increase their Performance in AcidCatalyzed Reactions. ChemSusChem 2019, 12 (3), 556-576.

(82) Knott, B. C.; Nimlos, C. T.; Robichaud, D. J.; Nimlos, M. R.; Kim, S.; Gounder, R. Consideration of the Aluminum Distribution in Zeolites in Theoretical and Experimental Catalysis Research. ACS Catal. 2018, 8 (2), 770-784.

(83) Dědeček, J.; Sobalík, Z.; Wichterlová, B. Siting and Distribution of Framework Aluminium Atoms in Silicon-Rich Zeolites and Impact on Catalysis. Catal. Rev.: Sci. Eng. 2012, 54 (2), 135-223.

(84) Lytle, F. W.; Via, G. H.; Sinfelt, J. H. X-Ray Absorption Spectroscopy: Catalyst Applications. In Synchrotron Radiation Research; Winick, H., Doniach, S., Eds.; Springer US: 1980; pp 401-424.

(85) Sayers, D. E.; Stern, E. A.; Lytle, F. W. New Technique for Investigating Noncrystalline Structures: Fourier Analysis of the Extended X-Ray-Absorption Fine Structure. Phys. Rev. Lett. 1971, 27 (18), 1204-1207.

(86) Segall, M. D.; Lindan, P. J. D.; Probert, M. J.; Pickard, C. J.; Hasnip, P. J.; Clark, S. J.; Payne, M. C. First-principles simulation: ideas, illustrations and the CASTEP code. J. Phys.: Condens. Matter 2002, 14 (11), 2717-2744.

(87) Loewenstein, W. The distribution of aluminum in the tetrahedra of silicates and aluminates. American Mineralogist: Journal of Earth and Planetary Materials 1954, 39 (1-2), 92-96.

(88) Clark-Baldwin, K.; Tierney, D. L.; Govindaswamy, N.; Gruff, E. S.; Kim, C.; Berg, J.; Koch, S. A.; Penner-Hahn, J. E. The Limitations of X-ray Absorption Spectroscopy for Determining the Structure of Zinc Sites in Proteins. When Is a Tetrathiolate Not a Tetrathiolate? J. Am. Chem. Soc. 1998, 120 (33), 8401-8409.

(89) Hennig, C.; Hallmeier, K.-H.; Zahn, G.; Tschwatschal, F.; Hennig, H. Conformational Influence of Dithiocarbazinic Acid Bishydrazone Ligands on the Structure of Zinc(II) Complexes: A Comparative XANES Study. Inorg. Chem. 1999, 38 (1), 38-43.

(90) Yachandra, V.; Powers, L.; Spiro, T. G. X-ray absorption spectra and the coordination number of zinc and cobalt carbonic anhydrase as a function of $\mathrm{pH}$ and inhibitor binding. J. Am. Chem. Soc. 1983, 105 (22), 6596-6604. 